\title{
Effects of relative humidity on aerosol light scattering: results from different European sites
}

\author{
P. Zieger ${ }^{1, *}$, R. Fierz-Schmidhauser ${ }^{1}$, E. Weingartner ${ }^{1}$, and U. Baltensperger ${ }^{1}$ \\ ${ }^{1}$ Paul Scherrer Institute, Laboratory of Atmospheric Chemistry, 5232 Villigen, Switzerland \\ *now at: Department of Applied Environmental Science, Stockholm University, 10691 Stockholm, Sweden
}

Correspondence to: P. Zieger (paul.zieger@alumni.ethz.ch)

Received: 17 March 2013 - Published in Atmos. Chem. Phys. Discuss.: 4 April 2013

Revised: 14 September 2013 - Accepted: 23 September 2013 - Published: 1 November 2013

\begin{abstract}
The effect of aerosol water uptake on the aerosol particle light scattering coefficient $\left(\sigma_{\mathrm{sp}}\right)$ is described in this study by comparing measurements from five European sites: the Jungfraujoch, located in the Swiss Alps at $3580 \mathrm{~m}$ a.s.l.; Ny-Ålesund, located on Spitsbergen in the Arctic; Mace Head, a coastal site in Ireland; Cabauw, a rural site in the Netherlands; and Melpitz, a regional background site in Eastern Germany. These sites were selected according to the aerosol type usually encountered at that location. The scattering enhancement factor $f(\mathrm{RH}, \lambda)$ is the key parameter to describe the effect of water uptake on the particle light scattering. It is defined as the $\sigma_{\mathrm{sp}}(\mathrm{RH})$ at a certain relative humidity $(\mathrm{RH})$ and wavelength $\lambda$ divided by its dry value. $f(\mathrm{RH})$ at the five sites varied widely, starting at very low values of $f(\mathrm{RH}=85 \%, \lambda=550 \mathrm{~nm})$ around 1.28 for mineral dust, and reaching up to 3.41 for Arctic aerosol. Hysteresis behavior was observed at all sites except at the Jungfraujoch (due to the absence of sea salt). Closure studies and Mie simulations showed that both size and chemical composition determine the magnitude of $f(\mathrm{RH})$. Both parameters are also needed to successfully predict $f(\mathrm{RH})$. Finally, the measurement results were compared to the widely used aerosol model, OPAC (Hess et al., 1998). Significant discrepancies were seen, especially at intermediate $\mathrm{RH}$ ranges; these were mainly attributed to inappropriate implementation of hygroscopic growth in the OPAC model. Replacement of the hygroscopic growth with values from the recent literature resulted in a clear improvement of the OPAC model.
\end{abstract}

\section{Introduction}

Atmospheric aerosols, which are defined as liquid or solid particles suspended in a gas (Seinfeld and Pandis, 2006), are tiny and usually invisible to our eyes. Nevertheless, they have an immense impact on our health and on our global climate. Aerosols scatter and absorb solar radiation, and, by doing so, they directly influence the Earth's radiation budget (see, e.g., Trenberth et al., 2009; Schwartz, 1996; Charlson et al., 1991). In addition, anthropogenic aerosol particles modify cloud properties, causing, e.g., brighter clouds with longer lifetimes and changed precipitation behavior (see, e.g. Lohmann and Leck, 2005; Ramaswamy et al., 2001; Twomey, 1977). The net effect of anthropogenic aerosols on the Earth's climate is cooling, in contrast to greenhouse gases, which have a warming effect. However, the Intergovernmental Panel on Climate Change (IPCC, 2007) concludes that the high uncertainty in the net radiative forcing of all main climate agents is mainly dominated by the large uncertainty in the aerosol radiative forcing. This is mainly caused by the high temporal, spatial, and compositional variability of the aerosol and the poorly understood and quantified aerosol effects.

Since aerosol particles can take up water, they can change in size and chemical composition depending on the ambient relative humidity $(\mathrm{RH})$. Therefore, long-term in situ measurements of aerosol optical and microphysical properties are usually performed at standardized dry conditions to avoid the RH effect when quantifying and characterizing the main aerosol properties (WMO/GAW, 2003). This is especially important for the aerosol particle light scattering coefficient $\sigma_{\mathrm{sp}}(\mathrm{RH}, \lambda)$ which strongly depends on $\mathrm{RH}$ ( $\lambda$ denotes the 
wavelength). These values measured at dry conditions differ significantly from the ambient and thus climate relevant ones. Knowledge of this RH effect is therefore of crucial importance for climate forcing calculations (see, e.g. Haywood and Shine, 1995; Pilinis et al., 1995). In addition, it is also needed for the comparison or validation of remote sensing with in situ measurements (see, e.g. Zieger et al., 2012, 2011; Morgan et al., 2010; Voss et al., 2001; Ferrare et al., 1998).

The key parameter to describe the influence of $\mathrm{RH}$ on the aerosol light scattering is the scattering enhancement factor $f(\mathrm{RH}, \lambda)$ :

$f(\mathrm{RH}, \lambda)=\frac{\sigma_{\mathrm{sp}}(\mathrm{RH}, \lambda)}{\sigma_{\mathrm{sp}}\left(\mathrm{RH}_{\mathrm{dry}}, \lambda\right)}$,

where $\sigma_{\mathrm{sp}}(\mathrm{RH}, \lambda)$ is the scattering coefficient at a defined $\mathrm{RH}$ and wavelength $\lambda$ and $\sigma_{\mathrm{sp}}\left(\mathrm{RH}_{\mathrm{dry}}, \lambda\right)$ is the corresponding dry scattering coefficient. $f(\mathrm{RH}, \lambda)$ will increase with increasing $\mathrm{RH}$ and will usually be $\geq 1$, if the particles do not experience significant restructuring when taking up water (Weingartner et al., 1995). $f(\mathrm{RH}, \lambda)$ depends on the size and on the chemical composition of the particle, because both of these parameters determine the particle's scattering properties and its ability to take up water. In the following, $f(\mathrm{RH})$ is discussed for the wavelength $\lambda=500 \mathrm{~nm}$ as an example; the explicit reference is omitted from now on for reasons of simplicity, since only a small wavelength dependency was observed at the five sites for the standard nephelometer wavelengths $(f(\mathrm{RH}=85 \%)$ varied $<5 \%$ for three wavelengths: $450,550$, and $700 \mathrm{~nm})$.

Several studies have measured and modeled $f(\mathrm{RH})$ for different aerosol types. Marine aerosols generally showed a higher $f(\mathrm{RH})$ and decreased with higher anthropogenic influence (see, e.g. Zieger et al., 2010; Fierz-Schmidhauser et al., 2010b; Wang et al., 2007; Carrico et al., 2003, 2000, 1998; Gasso et al., 2000; McInnes et al., 1998). Urban aerosols (see, e.g. Zieger et al., 2011; Yan et al., 2009; McInnes et al., 1998; Fitzgerald et al., 1982), or continental aerosol particles (see, e.g. Zieger et al., 2013, 2012; Fierz-Schmidhauser et al., 2010c; Sheridan et al., 2001) typically show intermediate values, while mineral dust dominated aerosols and pure biomass burning aerosols are characterized by low values of $f(\mathrm{RH})$ (see, e.g. Zieger et al., 2012; Fierz-Schmidhauser et al., 2010a; Kotchenruther and Hobbs, 1998; Li-Jones et al., 1998).

In this study, we present a comprehensive overview of the scattering enhancement measured at five European sites with a humidified nephelometer (Fierz-Schmidhauser et al., 2010c, see Sect. 3.1) during the years 2008 and 2009; we also present other aerosol measurements providing additional information. The sites were selected according to the aerosol type typically encountered at the sites, ranging from anthropogenically influenced urban or continental aerosol, to clean maritime and Arctic aerosol. The results of the different studies are compared to each other (Sect. 6.1) and to a widely used aerosol model (Sect. 6.4). Recommendations based on the results of the measurements and on comprehensive closure studies (Sects. 6.2 and 6.3) are given at the end of this study (Sect. 7).

\section{Site description}

A short description of the sites is given in this section and the reader is referred to the cited publications for more detailed information.

\subsection{Jungfraujoch}

Air masses at the high Alpine site Jungfraujoch (JFJ), located in the Swiss Alps $\left(46.55^{\circ} \mathrm{N}, 7.98^{\circ} \mathrm{E}, 3580 \mathrm{ma}\right.$ a.s.1.), were sampled in May 2008. These were mainly free tropospheric air masses, interspersed by transport events from the European atmospheric boundary layer (Henne et al., 2010), and occasionally even by long-range transported Saharan dust (Collaud Coen et al., 2004). Henne et al. (2010) characterized the JFJ site as being mainly remote. The JFJ is a monitoring site of the Global Atmosphere Watch (GAW) program by the World Meteorological Organization, and is part of the Aerosols, Clouds, and Trace gases Research InfraStructure network (ACTRIS), the European Monitoring and Evaluation Programme (EMEP) and the Swiss National Air Pollution Monitoring Network (NABEL). The results of the 2008 study are described in detail in Fierz-Schmidhauser et al. (2010a).

\section{$2.2 \quad \mathrm{Ny}$-Ålesund}

From July to October 2008, typical Arctic aerosol was measured at the Zeppelin station in Ny-Ålesund (NYA), located on the island of Spitsbergen $\left(78.92^{\circ} \mathrm{N}, 11.94^{\circ} \mathrm{E}\right)$. The period of the study was characterized by very low particle concentrations, and by distinct sea salt transport events reaching the station (which is located at an altitude of 475 ma.s.l.). Very clean conditions dominated here, since no local sources or long-range transport phenomena of pollutants (known as Arctic haze) were observed during this time of the year. NYA is also a GAW site and participates in the EMEP program. The results are presented in Zieger et al. (2010).

\subsection{Mace Head}

In January and February 2009, air masses at the Mace Head (MHD) station in Ireland $\left(53.33^{\circ} \mathrm{N}, 9.91^{\circ} \mathrm{W}, 5 \mathrm{ma}\right.$ a.s.l.) were measured; these air masses were mainly marine, however there were occasional non-marine and polluted air masses. The station is located on the west coast of Ireland close to the shore of the ocean. Henne et al. (2010) categorized the MHD site as generally remote with a low population influence. MHD is a GAW site, and joined the ACTRIS and EMEP programs as well. A detailed analysis of this field campaign is given in Fierz-Schmidhauser et al. (2010b). 


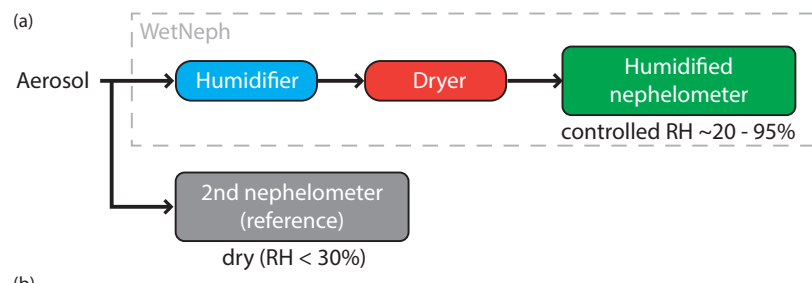

(b)

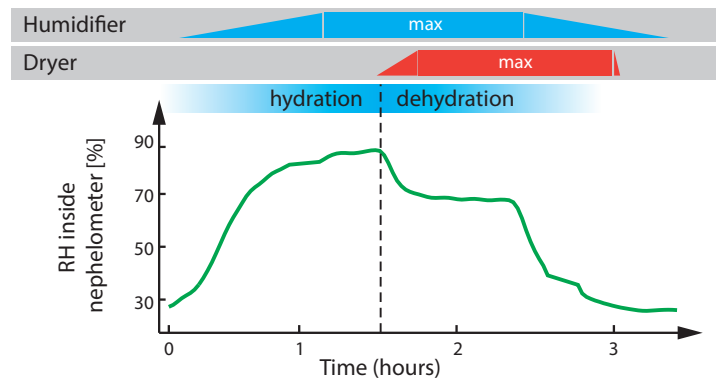

Fig. 1. (a) Block diagram of the WetNeph setup consisting of a humidifier, a dryer, and a modified nephelometer. A second nephelometer was always operated in parallel as a reference instrument. (b) Schematic time profile of the relative humidity inside the humidified nephelometer. The performance of the humidifier and dryer is shown schematically above the diagram. More technical details can be found in Fierz-Schmidhauser et al. (2010c).

\subsection{Melpitz}

Field measurements were performed at the central European research station Melpitz (MEL) in Germany $\left(51.53^{\circ} \mathrm{N}\right.$, $12.92^{\circ}$ E, 86 ma.s.1.), in January and February 2009. MEL is a rural site surrounded by fields, forests and small villages. The nearest large city is Leipzig, located $\approx 50 \mathrm{~km}$ southwest of the site. Mainly anthropogenically influenced air masses with few transported sea salt events were observed. MEL is an observation site within EMEP, GAW, ACTRIS and GUAN (German Ultrafine Aerosol Network, Birmili et al., 2009). A detailed description of the intensive campaign is given in Zieger et al. (2013).

\subsection{Cabauw}

The Cabauw site $(\mathrm{CAB})$ is located in the Netherlands in a rural area between the cities of Utrecht and Rotterdam $\left(51.97^{\circ} \mathrm{N}, 4.93^{\circ} \mathrm{E}\right)$. It is therefore influenced by transported pollution from the European continent, by local sources, and by the marine environment. Henne et al. (2010) characterized the $\mathrm{CAB}$ site as one impacted by relatively large pollution burdens that may strongly depend on wind direction. CAB participates in the ACTRIS and EMEP programs. During the measurement period between June and October 2009, the aerosol at $\mathrm{CAB}$ showed high variability in composition. This work is described in Zieger et al. (2011).

\section{Experimental}

\subsection{Particle light scattering measurements at elevated relative humidity}

The particle light scattering coefficient at elevated RH was measured with a humidified nephelometer (WetNeph), which was developed at the Paul Scherrer Institute (PSI). The WetNeph is described in detail in Fierz-Schmidhauser et al. (2010c) and only a brief description will be given here. The aerosol is directed from the inlet to a humidification system, where the particles are exposed to high RH between $30 \%$ and $90 \%$. Following this, the particles are dried again to low RH (usually to $\mathrm{RH} \approx 50 \%$ ) in a Nafion dryer. The particle scattering coefficients are then measured in a modified nephelometer (TSI Inc., Model 3563) at three wavelengths $(\lambda=450,550$ and $700 \mathrm{~nm})$. A schematic diagram showing the WetNeph set-up is shown in Fig. 1a. The WetNeph can be operated in a constant elevated RH mode (usually at $\mathrm{RH}=85 \%$ inside the nephelometer cell) or in the humidograph mode. In the latter, the aerosol stream is first exposed to an increasing $\mathrm{RH}$ in the humidifier with the dryer being turned off (hydration) until a high RH has been reached inside the nephelometer (usually $\mathrm{RH} \approx 85 \%$ depending on the flow and surrounding temperature conditions). The aerosol can then be dried back to low RH by keeping the humidifier at maximum RH and the dryer turned on (dehydration). The humidograph mode and the timeline of the RH inside the humidified nephelometer is shown schematically in Fig. 1b. With this set-up, both branches of the aerosol's hysteresis curve can be characterized. It should be mentioned that the deliquescence RH observed in the humidograms is not identical to the thermodynamically deliquescence $\mathrm{RH}$; this is because the particles have experienced the highest RH within the humidifier, while the RH slightly decreases until the light scattering is measured in the nephelometer. The efflorescence (during the dehydration mode) cannot be observed with the WetNeph due to the limitations of the dryer, which was usually only operated at a minimum of $50 \% \mathrm{RH}$. A reference nephelometer (TSI Inc., Model 3563) was always operated in parallel at dry conditions (DryNeph). To retrieve the full hemispheric scattering coefficients and to correct for the nonideal light source, the recorded nephelometer data has to be corrected, e.g., by using the proposed scheme by Anderson et al. (1996). This correction scheme is based on the measured Ångström exponent. The increasing uncertainties for coarse mode dominated aerosol can be reduced if the measured size distribution (ideally as a function of $\mathrm{RH}$ ) is taken into account; this has not been done in this study due to the predominance of fine mode aerosol. Besides the routine nephelometer calibration with standard gas, knowledge of the precise RH inside the nephelometer cell is of crucial importance. This is established by an additional dew point mirror within the system and regular calibrations of the different RH sensors using standard salt solutions. The WetNeph 
Table 1. Overview of the instrumentation used at the investigated sites.

\begin{tabular}{|c|c|c|c|c|c|c|}
\hline Parameter & Employed instrument & $\begin{array}{l}\text { Jungfraujoch } \\
\text { JFJ }\end{array}$ & $\begin{array}{l}\text { Ny-Ålesund } \\
\text { NYA }\end{array}$ & $\begin{array}{l}\text { Mace Head } \\
\text { MHD }\end{array}$ & $\begin{array}{l}\text { Melpitz } \\
\text { MEL }\end{array}$ & $\begin{array}{l}\text { Cabauw } \\
\text { CAB }\end{array}$ \\
\hline \multirow[t]{2}{*}{ Particle light scattering coefficient } & $\begin{array}{l}\text { Humidified nephelometer } \\
\text { (WetNeph) }\end{array}$ & $\mathrm{x}$ & $\mathrm{x}$ & $\mathrm{x}$ & $\mathrm{x}$ & $\mathrm{x}$ \\
\hline & Nephelometer (DryNeph) & $\mathrm{x}$ & $\mathrm{x}$ & $\mathrm{x}$ & $\mathrm{x}$ & $\mathrm{x}$ \\
\hline \multirow[t]{2}{*}{ Particle light absorption coefficient } & Aethalometer & $\mathrm{x}$ & $\mathrm{x}$ & $\mathrm{x}$ & - & $x^{f}$ \\
\hline & $\begin{array}{l}\text { Multi-angle absorption } \\
\text { photometer (MAAP) }\end{array}$ & $\mathrm{x}$ & - & - & $\mathrm{x}$ & $\mathrm{x}$ \\
\hline \multirow[t]{4}{*}{ Particle number size distribution } & $\begin{array}{l}\text { Scanning mobility particle } \\
\text { sizer (SMPS) }\end{array}$ & $\mathrm{x}$ & $x$ & $\mathrm{x}$ & - & $x^{f}$ \\
\hline & $\begin{array}{l}\text { Dual mobility particle size } \\
\text { spectrometer (DMPSS) }\end{array}$ & - & - & - & $\mathrm{x}$ & - \\
\hline & $\begin{array}{l}\text { Optical particle size } \\
\text { spectrometer (OPSS) }\end{array}$ & $\mathrm{x}$ & $\mathrm{x}$ & $\mathrm{x}$ & $\mathrm{x}$ & - \\
\hline & $\begin{array}{l}\text { Aerodynamic particle sizer } \\
\text { (APS) }\end{array}$ & - & - & - & - & $\mathrm{x}$ \\
\hline Hygroscopic growth factor & $\begin{array}{l}\text { Hygroscopic tandem } \\
\text { differential mobility analyzer } \\
\text { (H-TDMA) }\end{array}$ & $x^{f}$ & - & $\mathrm{x}$ & $x^{f}$ & $x^{f}$ \\
\hline \multirow[t]{2}{*}{ Chemical composition } & $\begin{array}{l}\text { Aerosol mass spectrometer } \\
\text { (AMS) }\end{array}$ & $\mathrm{x}$ & - & - & $\mathrm{x}$ & - \\
\hline & Filter measurements & - & $\mathrm{x}$ & - & $\mathrm{x}$ & - \\
\hline \multirow[t]{3}{*}{ Location } & & Switzerland & Spitsbergen & Ireland & Germany & The Netherlands \\
\hline & & $46.55^{\circ} \mathrm{N}, 7.98^{\circ} \mathrm{E}$ & $78.92^{\circ} \mathrm{N}, 11.94^{\circ} \mathrm{E}$ & $53.33^{\circ} \mathrm{N}, 9.91^{\circ} \mathrm{W}$ & $51.53^{\circ} \mathrm{N}, 12.92^{\circ} \mathrm{E}$ & $51.97^{\circ} \mathrm{N}, 4.93^{\circ} \mathrm{E}$ \\
\hline & & 3580 m a.s.l. & $475 \mathrm{~m}$ a.s.l. & 5 ma.s.1. & $86 \mathrm{~m}$ a.s.l. & $1 \mathrm{~m}$ a.s.l. \\
\hline Time period (days) & & May 2008 (31) & Jul-Oct 2008 (91) & Jan-Feb 2009 (28) & Feb-Mar 2009 (36) & Jun-Oct 2009 (120) \\
\hline
\end{tabular}

${ }^{\mathrm{a}}$ Fierz-Schmidhauser et al. (2010a), ${ }^{\mathrm{b}}$ Zieger et al. (2010), ${ }^{\mathrm{c}}$ Fierz-Schmidhauser et al. (2010b), ${ }^{\mathrm{d}}$ Zieger et al. (2013), ${ }^{\mathrm{e}}$ Zieger et al. (2011), ${ }^{\mathrm{f}}$ Data only partly available.

system has additionally been validated using monodisperse salt measurements of ammonium sulfate and sodium chloride and by applying Mie theory (Fierz-Schmidhauser et al., 2010c).

Two main factors contribute to the uncertainty of the measured $f(\mathrm{RH})$ : the uncertainty of the particle scattering coefficient measured by the two nephelometers (approx. 10\%, Anderson et al., 1996) and the uncertainty of the RH inside the humidified nephelometer (1.5-2 percent points in RH, see Fierz-Schmidhauser et al., 2010c). The uncertainty of the $\mathrm{RH}$ sensor can be included to the total $f(\mathrm{RH})$ uncertainty at a given $\mathrm{RH}$ if an empirical course of $f(\mathrm{RH})$ is assumed (see e.g. Eq. 8 in Zieger et al., 2010). The resulting relative uncertainty then increases with the increasing hygroscopicity and increasing $\mathrm{RH}$ (and vice versa). At $\mathrm{RH}=85 \%$, the relative error in $f(\mathrm{RH})$ due to the $\mathrm{RH}$ sensor error is smaller than $14 \%$ for very hygroscopic aerosols like sea salt. Both main error sources propagate to a total relative uncertainty for $f(\mathrm{RH}=85 \%)$ smaller than $20 \%$.

\subsection{Additional aerosol measurements}

A large variety of further aerosol parameters was measured in parallel during all field campaigns. The data was needed to describe the physical and chemical properties responsible for the encountered scattering enhancement, to search for other proxies to predict $f(\mathrm{RH})$, and for relevant closure studies. Table 1 gives an overview of the instrumentation employed at the different sites. Here, only a brief description will be given. More details can be found in the individual publications and in the the references therein.
The particle light absorption coefficient was measured using either a multi-wavelength aethalometer (Magee Scientific, Model AE-31) or a single-wavelength multi-angle absorption photometer (MAAP; Thermo Scientific Inc., Model 5012). The MAAP measures the light attenuation and light scattered back from aerosol particles that have been deposited on a filter. A radiative transfer scheme is applied to retrieve the fraction of light absorbed by the deposited aerosol (with a $12 \%$ rel. uncertainty Petzold and Schönlinner, 2004). The aerosol absorption coefficient $\sigma_{\text {ap }}$ is obtained by multiplying the measured black carbon (BC) mass concentration with the instrumental set value of the mass absorption cross section $\left(6.6 \mathrm{~m}^{2} \mathrm{~g}^{-1}\right)$. The aethalometer measures the light attenuation by the aerosol particles (also deposited on a filter) at 7 wavelengths. The aerosol absorption coefficients were derived by a formula given by Weingartner et al. (2003) and corrected for site-specific filter effects using values given by Collaud Coen et al. (2010).

The particle number size distribution of the fine mode particles (diameter $D<1 \mu \mathrm{m}$ ) was either characterized using a scanning mobility particle sizer (SMPS) or a dual mobility particle size spectrometer (DMPSS), while the coarse mode particles $(D>1 \mu \mathrm{m})$ were measured using either an aerodynamic particle sizer (APS) or an optical particle size spectrometer (OPSS). The SMPS (at CAB: TSI Inc., Model 3034 (modified); at JFJ, NYA, MHD: custom build instrument, see references in Table 1) and DMPSS (custom build instrument; Birmili et al., 2009) measure an electrical mobility diameter between 10 and approximately $800 \mathrm{~nm}$. For both instrument types, the particles are charged and then size selected by a differential mobility analyzer (DMA) before 
they are counted by condensation particle counter (CPC). The DMPSS at MEL consists of two DMA that measure an extended size range, starting from $4 \mathrm{~nm}$. A correction for multiple charged particles has to be applied for all measurements of DMPSS and SMPS. These uncertainties for the fine mode particles measured by the SMPS or DMPSS lie within the findings of Wiedensohler et al. (2012) and are clearly below $10 \%$ for particles between $20-200 \mathrm{~nm}$, while the uncertainties can increase up to $30 \%$ for particles $>200 \mathrm{~nm}$. The APS (TSI Inc., 3321) measures the particle number size distribution with an aerodynamic particle diameter between approx. 0.5 and $20 \mu \mathrm{m}$. It uses a time-of-flight method by using two laser beams to measure the time and to count the particles. The measured distributions have to be corrected for nonsphericity and the density of the ambient aerosol (Marshall et al., 1991), since the APS is calibrated with standardized spherical polystyrene latex particles. The counting and sizing uncertainty of the APS for particles with diameters $>1 \mu \mathrm{m}$ is below $10 \%$ (5-8\% as e.g. reported by Putaud et al., 2000), but the counting uncertainty may significantly increase for smaller particles. The OPSS (Grimm GmbH, Dust Monitor 1.108) measures an optical diameter between 0.3 and $25 \mu \mathrm{m}$. The instrument uses the light intensity that is scattered by the particles from the light emitted by a laser diode. The counting efficiency of the OPSS is believed to be between $90-100 \%$ (Heim et al., 2008). The optical particle diameter, however, depends on the refractive index of the particles, which has to be corrected for (see e.g. Bukowiecki et al., 2011), as it is important, especially for the surface, volume, and mass determination. Here, we assume an uncertainty of $20 \%$ in the OPSS particle sizing (see Appendix for more details).

The hygroscopic growth factor, defined as the ratio of the particle diameter at high RH to its dry value (see Eq. (2) below), was added to the analysis using measurements of a hygroscopic tandem differential mobility analyzer (H-TDMA; see e.g. Liu et al., 1978). The aerosol sample is first dried in the H-TDMA and is then charged by a bipolar charger. A dry size class of particles with the diameter of $D_{\text {dry }}$ is then selected by a DMA, before the particles are exposed to controlled RH (90\%) and temperature. The wet particles are sized by the second DMA and are subsequently counted by a CPC. A humidified size distribution for a certain $D_{\text {dry }}$ is then obtained. The hygroscopic growth factors were inverted from the humidified distributions using the procedure described by Gysel et al. (2009). All instruments were set to measure the hygroscopic growth factors of $D_{\mathrm{dry}}=35,50$, $75,110,165$ and $265 \mathrm{~nm}$ ( $265 \mathrm{~nm}$ was not measured at CAB, at MHD only $165 \mathrm{~nm}$ was used as dry diameter). The growth factors in these studies were determined within \pm 0.05 , which is typical for a well-maintained TDMA system (Swietlicki et al., 2008). All H-TDMA instruments were custom-built, and more technical details can be found in the references given in Table 1.

The Aerodyne high resolution time-of-flight aerosol mass spectrometer (AMS; Aerodyne Research) measured the chemical composition of non-refractory particles with diameters smaller than $1 \mu \mathrm{m}$ (vacuum aerodynamic particle diameter). The aerosol is introduced into the instrument via an aerodynamic lens which focuses the aerosol into a tight beam. The particle beam impacts a heated tungsten plate, where the components are flash vaporized. The resulting gas plume is ionized and the mass spectrum is being recorded using a high mass resolution spectrometer. Because soot, crustal material and sea-salts cannot be detected, the AMS is commonly considered to provide non-refractory $\mathrm{PM}_{1}$ (particulate matter with a particle diameter $<1 \mu \mathrm{m}$ ) aerosol particle chemical composition. Only mass fractions were used in our data analysis, which avoids systematic error (e.g., due to the collection efficiency of the AMS). The relative ionization efficiency would result in an error of the mass ratios of approximately $10 \%$. The AMS has been characterized in detail, e.g. by DeCarlo et al. (2006) or Canagaratna et al. (2007).

At MEL and NYA, aerosol particles were also collected on daily $\mathrm{PM}_{10}$ high volume filter samples. The results were only needed to identify sea salt transport events to the station.

Part of these in situ measured parameters, together with $\sigma_{\mathrm{sp}}(\mathrm{RH})$, were used to retrieve the particle light extinction coefficient at ambient $\mathrm{RH}$, which was either compared to remote sensing measurements of lidar instruments (light detection and ranging; see Zieger et al., 2011, 2012) or to the retrieval of MAX-DOAS measurements (multi-axis differential optical absorption spectroscopy; see Zieger et al., 2011). A good agreement between LIDAR and in situ measurements was found, giving further confidence to our findings.

\section{Modeling $f(\mathbf{R H})$}

The scattering enhancement can be modeled using Mie theory (Mie, 1908). It was assumed that the particles in our study were spherical, homogeneous, and internally or externally mixed. The Mie code used here is based on a computer routine developed by Bohren and Huffman (2004). The complex refractive index and the particle number size distribution are required inputs.

The change in particle diameter due to water uptake is usually described with the hygroscopic growth factor $g(\mathrm{RH})$, which is defined as

$g(\mathrm{RH})=\frac{D_{\mathrm{wet}}(\mathrm{RH})}{D_{\mathrm{dry}}}$,

where $D_{\text {dry }}$ is the dry particle diameter and $D_{\text {wet }}(\mathrm{RH})$ the diameter at a specific RH. The hygroscopic growth as a function of RH is physically described by the Köhler theory (Köhler, 1936). The RH dependence of Eq. (2) can be parameterized using a one-parameter relationship which has been introduced, e.g., by Petters and Kreidenweis (2007):

$g\left(a_{\mathrm{W}}\right)=\left(1+\kappa \frac{a_{\mathrm{w}}}{1-a_{\mathrm{w}}}\right)^{\frac{1}{3}}$, 
where $a_{\mathrm{w}}$ is the water activity, which can be replaced by $\mathrm{RH}$, if the Kelvin effect can be neglected. This simplification is justified in our study, because the Kelvin term within the Köhler equation is small for large particles $(D>80 \mathrm{~nm})$, which are important for light scattering at the wavelengths used here. The parameter $\kappa$ in Eq. (3) captures all solute properties of the particles (Raoult effect) and is a simple measure of the particle's hygroscopicity, when spherical particles with individual homogeneous composition are assumed.

The change of the size distribution and the refractive index with changing RH (needed for the Mie calculations) can be calculated with the following procedure: the increase of the particle diameter is determined by multiplying the dry diameter $D_{\text {dry }}$ by the (dry) size dependent hygroscopic growth factor $g\left(\mathrm{RH}, D_{\mathrm{dry}}\right)$.

$D_{\text {wet }}(\mathrm{RH})=g\left(\mathrm{RH}, D_{\text {dry }}\right) D_{\text {dry }}$

The particle number size distribution is then calculated as follows:

$\frac{\mathrm{d} \tilde{N}\left(D_{\text {wet }}\right)}{\mathrm{d} \log D_{\text {wet }}}=\frac{\mathrm{d} N\left(D_{\text {dry }}\right)}{\mathrm{d} \log D_{\text {dry }}} \frac{D_{\text {wet }}}{D_{\text {dry }}} \frac{\mathrm{d} D_{\text {dry }}}{\mathrm{d} D_{\text {wet }}}$.

The change of the dry refractive index is calculated by applying a volume weighting of the dry refractive index $m_{\text {dry }}$ with the refractive index of water $m_{\mathrm{H}_{2} \mathrm{O}}$ (Hale and Querry, 1973):

$m_{\mathrm{wet}}=\frac{m_{\mathrm{dry}}+m_{\mathrm{H}_{2} \mathrm{O}}\left(g(\mathrm{RH})^{3}-1\right)}{g(\mathrm{RH})^{3}}$.

For high growth factors and high values of $\mathrm{RH}$, the refractive index of the aerosol droplet approaches that of water. Although several other mixing rules for the refractive index exist, the volume weighted average was found by Nessler et al. (2005b) to be the most suitable one, since the differences between the different methods are very small, and the volume weighting formula is the simplest one to use. $m_{\text {wet }}$ and $\frac{\mathrm{d} \tilde{N}\left(D_{\text {wet }}\right)}{\mathrm{d} \log D_{\text {wet }}}$ are then the input parameters for the Mie code to calculate the aerosol optical parameters at a specific $\mathrm{RH}$ and wavelength.

Figure 2 shows $f(\mathrm{RH}, \lambda=589 \mathrm{~nm})$ as an example for different inorganic salts and for a typical organic substance at a fixed RH of $85 \%$. A monomodal lognormal size distribution with a standard deviation of 1.8 was assumed. The refractive indices were taken from Seinfeld and Pandis (2006) and Nessler et al. (2005a), and the hygroscopic growth factors were taken from Topping et al. (2005) and Sjogren et al. (2008). It can be seen that both size and chemical composition matter when determining the scattering enhancement. The chemical composition is important for the refractive index, and even more important for the actual hygroscopic growth of the particle. Sodium chloride is one of the most hygroscopic salts and therefore shows the largest values of $f(\mathrm{RH})$, e.g. a lognormal distribution of pure $\mathrm{NaCl}$ particle

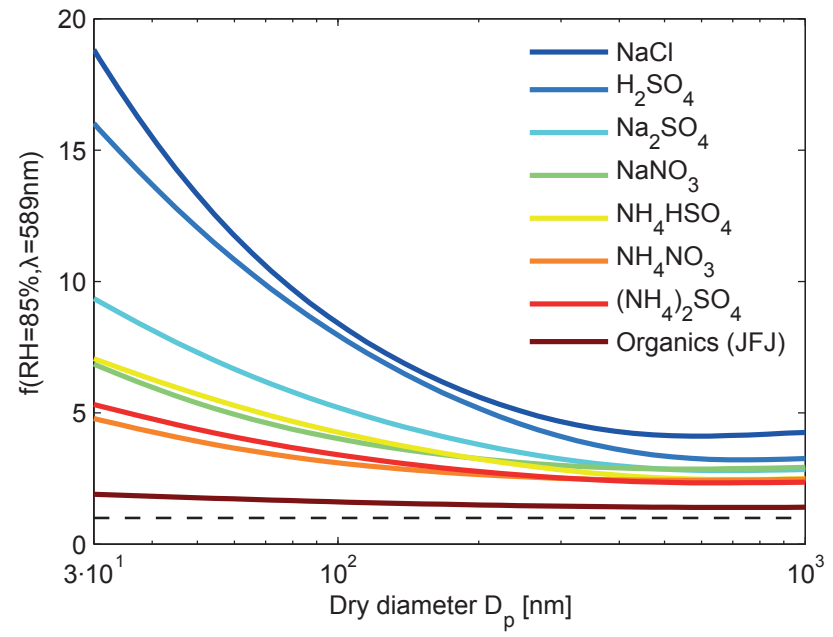

Fig. 2. The scattering enhancement $f(\mathrm{RH})$ at $\mathrm{RH}=85 \%$ and $\lambda=589 \mathrm{~nm}$ vs. dry particle diameter calculated for different inorganic salts (see legend) and for organics (typically found at the Jungfraujoch, JFJ). A monomodal size distribution is assumed $(\sigma=1.8)$. The hygroscopic growth factors were taken from Topping et al. (2005); Sjogren et al. (2008), and the refractive indices were taken from Seinfeld and Pandis (2006) and Nessler et al. (2005a).

with a mode diameter of $100 \mathrm{~nm}$ will scatter at $85 \%$ RH approximately eight times more than in dry conditions. Figure 2 also shows the possibility of compensating effects between size and chemical composition: a small, less hygroscopic particle (e.g., $\mathrm{NH}_{4} \mathrm{HSO}_{4}$ ) can have the same magnitude of $f(\mathrm{RH})$ as a large, more hygroscopic particle (e.g. $\mathrm{NaCl}$ ). The rather large values of $f(\mathrm{RH})$ at small diameters in Fig. 2 have been reproduced with monodisperse salt measurements in Fierz-Schmidhauser et al. (2010c), where they have been used to assure the measurement quality of our instrument (see Sect. 3.1).

\section{Closure studies}

One goal of our work was to calculate and predict the scattering enhancement using auxiliary measurements, like size distribution, hygroscopic growth, and chemical composition and applying Mie calculations. The first task was to check for consistency within the in situ measurements performing socalled closure studies. A closure is achieved if an appropriate model (here a model based on Mie theory, see Sect. 4) can be used to reproduce the observation of interest by applying a different set of observational data. If the reproduced values (including the model uncertainty) lie within the measurement uncertainty, the closure can be considered achieved.

In a next step, sensitivity studies were performed to search for independently measured parameters that can be used to predict $f(\mathrm{RH})$. If the auxiliary aerosol measurements are operated on a continuous basis, e.g., within a monitoring program, they can possibly be used to predict $f(\mathrm{RH})$ without 
Table 2. Mean, standard deviation (STD), and percentile values of $f(\mathrm{RH}=85 \%, 550 \mathrm{~nm}$ ) for the Jungfraujoch (JFJ), Ny-Ålesund (NYA), Mace Head (MHD), Melpitz (MEL), and Cabauw (CAB). Average values are also given for different air mass types, if a differentiation of specific air masses was possible during the individual measurement periods.

\begin{tabular}{lccccc}
\hline Station: Type & Mean & STD & 75 th prctl. & Median & 25th prctl. \\
\hline JFJ: All & 2.30 & 0.33 & 2.52 & 2.34 & 2.12 \\
JFJ: Free tropospheric/PBL influenced & 2.32 & 0.31 & 2.53 & 2.35 & 2.13 \\
JFJ: Saharan dust influenced & 1.28 & 0.10 & 1.35 & 1.27 & 1.20 \\
\hline NYA: All & 3.24 & 0.63 & 3.63 & 3.12 & 2.79 \\
NYA: Sea salt & 2.86 & 0.41 & 3.05 & 2.81 & 2.56 \\
NYA: Arctic (no sea salt) & 3.41 & 0.66 & 3.71 & 3.28 & 3.05 \\
\hline MHD: All & 2.08 & 0.29 & 2.30 & 2.11 & 1.87 \\
MHD: Clean sector (sea salt) & 2.28 & 0.19 & 2.37 & 2.29 & 2.17 \\
MHD: Polluted sector & 1.80 & 0.26 & 1.96 & 1.82 & 1.66 \\
\hline MEL: All & 2.77 & 0.37 & 3.02 & 2.78 & 2.56 \\
\hline CAB: All & 2.38 & 0.38 & 2.63 & 2.34 & 2.14 \\
CAB: Maritime & 3.38 & 0.31 & 3.60 & 3.38 & 3.16 \\
CAB: Continental south & 1.86 & 0.17 & 2.02 & 1.86 & 1.76 \\
CAB: Maritime, heavily polluted & 1.95 & 0.14 & 2.04 & 2.00 & 1.82 \\
CAB: Maritime, slightly polluted & 2.97 & 0.20 & 3.11 & 2.96 & 2.81 \\
CAB: Continental east & 2.25 & 0.16 & 2.37 & 2.26 & 2.13 \\
\hline
\end{tabular}

explicit RH-dependent optical measurements using, e.g., a humidified nephelometer. Unfortunately, the available suite of aerosol instruments was not identical within the five field campaigns. An overview of the main measurements, the instrument abbreviations, and campaign time frames can be found in Table 1. The optical parameters (scattering coefficient at defined RH and at dry conditions, as well as the absorption coefficient) were almost completely measured at all sites, while the applied aerosol in situ techniques varied from site to site. At JFJ, a comprehensive set of instruments were operated. In particular, the bulk aerosol chemical composition was determined with an AMS. The AMS measurements were used together with aethalometer measurements to calculate (a) the hygroscopic growth factor (in addition to the direct measurement of the H-TDMA) and (b) the complex refractive index, which is needed as an input parameter for the Mie calculations. The complex refractive indices (at $\lambda=550 \mathrm{~nm}$ ) used were 1.48 for organics, 1.556 for $\mathrm{NH}_{4} \mathrm{NO}_{3}, 1.530$ for $\left(\mathrm{NH}_{4}\right)_{2} \mathrm{SO}_{4}, 1.473$ for $\mathrm{NH}_{4} \mathrm{HSO}_{4}, 1.434$ for $\mathrm{H}_{2} \mathrm{SO}_{4}$, and $1.75+0.44 i$ for $\mathrm{BC}$ (for the specific references and details see Fierz-Schmidhauser et al., 2010a). The imaginary part was omitted for all components except for BC. The mean hygroscopic growth factor is calculated from the growth factors, densities and volume fractions of the individual components using the ZSR relationship (Stokes and Robinson, 1966). At NYA, the chemical composition was only partly determined by filter measurements (which were limited to inorganic substances). The hygroscopic growth factor was also not measured directly using, e.g., a H-TDMA; instead it was retrieved by Mie theory through an inverse calculation using the measured size distribution, the optical measurements, and an assumption about the refractive index (see Zieger et al., 2010, for more details). At MHD, all relevant aerosol measurements except for chemical measurements were available during the observation period. During the entire two months' campaign, MEL provided filter measurements and detailed chemical composition measurements with an AMS. The hygroscopic growth measurements using the H-TDMA were only partly available. At CAB, no chemical measurements at all were available during the observation period, but a H-TDMA was partly deployed. For the closure studies, the SMPS or DMPSS is probably the most important instrument since it measures the particle number concentration in the optically relevant size range usually up to $\approx 550-800 \mathrm{~nm}$ with a high precision. It was in operation at all five sites (unfortunately only for two weeks within the four month's campaign at $\mathrm{CAB}$ ).

\section{Results}

\subsection{Comparison of the different measurement sites}

The measured scattering enhancement factor $f(\mathrm{RH})$ showed individual characteristics significant for each of the five sites. Figure 3 shows FLEXTRA trajectories (Stohl et al., 1995; Stohl and Seibert, 1998) for each site color-coded by the $f(\mathrm{RH}=85 \%)$ value measured at the time of the air parcel arriving at the site. Only periods with available WetNeph measurements are shown. The mean, standard deviation, and percentile values of $f(\mathrm{RH}=85 \%)$ are given in Table 2 . 


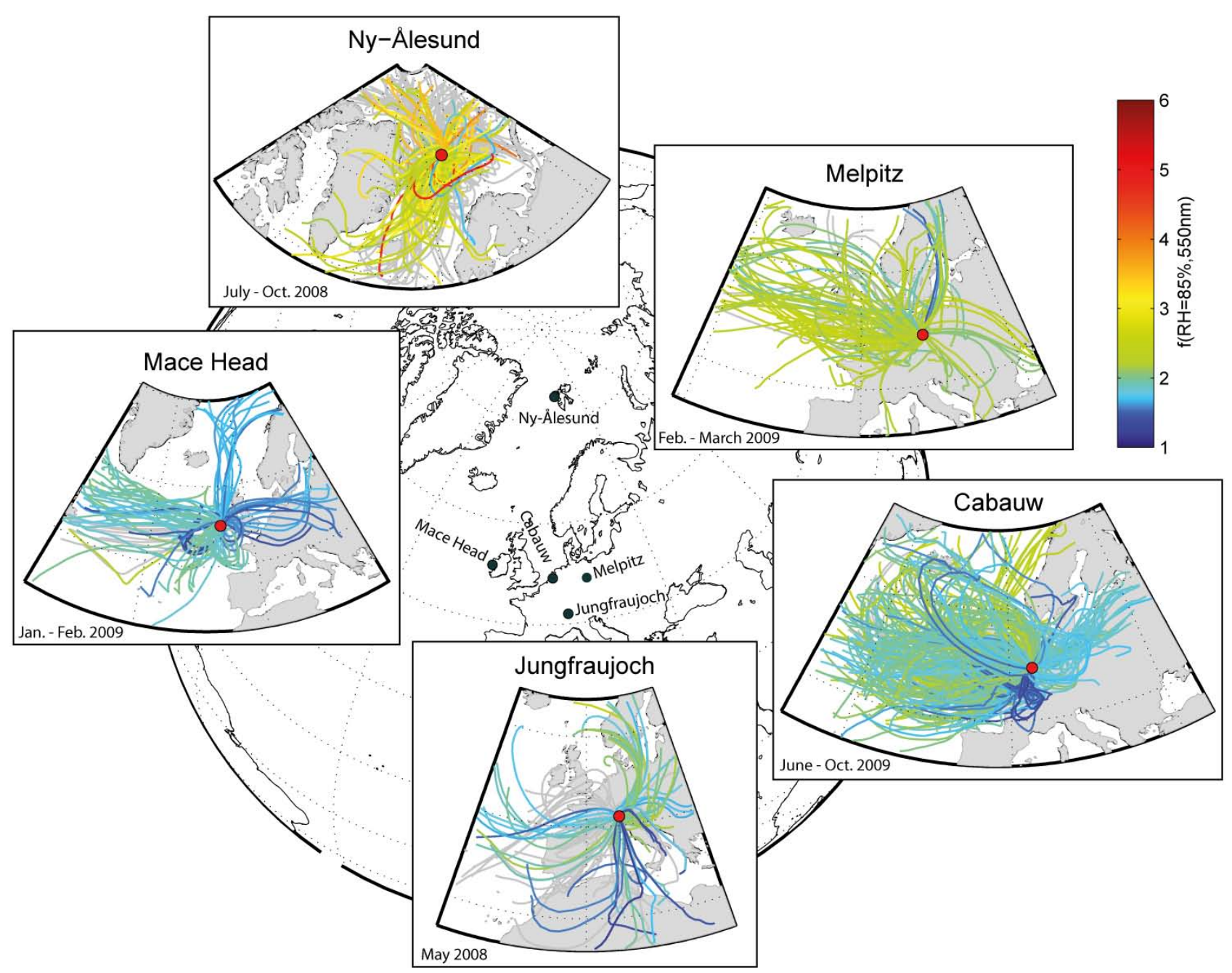

Fig. 3. $72 \mathrm{~h}$ air mass back trajectories (FLEXTRA) color-coded by the $f(\mathrm{RH}=85 \%, 550 \mathrm{~nm})$ measured at the time the air parcel arrived at the site.

For JFJ, Fig. 3 reveals that the air masses mainly originated from central Europe but also had their origin in the north African regions. These air masses transported mineral dust particles up to JFJ in what if often called a Saharan dust event (SDE). Since mineral dust shows low hygroscopic growth, its $f(\mathrm{RH}=85 \%)$ values are low compared to those of other air masses.

At $\mathrm{CAB}$, air masses with low $f(\mathrm{RH}=85 \%)$ values mainly originated in industrialized areas of, e.g. the Ruhr area, Northern France, Southern Britain, the Netherlands, and Belgium. $f(\mathrm{RH}=85 \%)$ was elevated at $\mathrm{CAB}$ when the air masses originated from the Atlantic Ocean or the Northern Sea and contained hygroscopic sea salt. However, only a few clear sea salt events were observed at $\mathrm{CAB}$, showing hysteresis behavior as one would expect from, e.g., relatively pure inorganic salts like $\mathrm{NaCl}$.

The clean and polluted sectors can be identified at MHD: $f(\mathrm{RH})$ was generally higher when air masses arrived from the sea (mean $f(\mathrm{RH}=85 \%)=2.28$ ), while the air masses from the polluted eastern sector, which had contact with the urban areas of Ireland and the UK, were characterized by smaller values (mean $f(\mathrm{RH}=85 \%)=1.8$ ). The maritime air masses with dominating sea salt were also seen in the hysteresis behavior of the recorded humidograms.

MEL showed generally larger values of $f(\mathrm{RH})$ (mean $f(\mathrm{RH}=85 \%)=2.77)$, with air masses originating mainly from the western and northwestern part of Europe. No distinct sectors could be identified during the observation period in winter 2009. Sea salt with coincident hysteresis in the humidograms was observed at MEL.

As an extreme, the NYA site showed the largest $f(\mathrm{RH}=85 \%)$ (which could range up to values of 6.6) compared to the other sites. The main source areas at NYA were the open oceans and ice shields of the Arctic, which brought pure sea salt in addition to fine mode-dominated secondary aerosol to the site. No clear long-range transport of pollution 


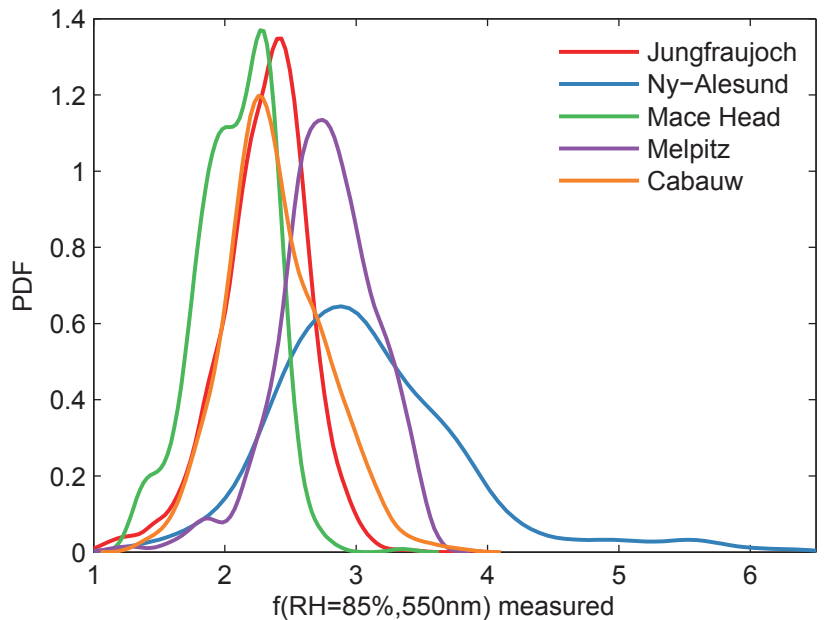

Fig. 4. Probability density function (PDF) of measured scattering enhancement $f(\mathrm{RH}=85 \%, 550 \mathrm{~nm})$ at the different sites (see legend).

to the measurement site was observed during summer and fall 2008. The mean values for non-sea salt influenced periods were higher (mean $f(\mathrm{RH}=85 \%)=3.41)$ than the sea salt influenced periods (mean $f(\mathrm{RH}=85 \%)=2.86$ ). This was attributed to compensation effects of size and hygroscopicity: smaller and less hygroscopic particles can have similar (or even larger) values of $f(\mathrm{RH})$ than larger and more hygroscopic particles (see Fig. 2).

The $f(\mathrm{RH}=85 \%)$-values measured at all five sites are shown as probability density functions (PDF) in Fig. 4. The two-sector discrimination of MHD can be clearly seen (area below the first two shoulders of the PDF is representative for air masses from the polluted sector, the area below the maxima at approx. $f(\mathrm{RH}=85 \%, 550 \mathrm{~nm})=2.1$ is mainly caused by values originating from the clean sector). JFJ, MEL and MHD show similar values of $f(\mathrm{RH}=85 \%)$, while MEL and especially NYA are characterized by generally larger values. The larger values at NYA can be explained by the absence of anthropogenic influence and by the size and hygroscopicity of the particles.

Example humidograms of $f(\mathrm{RH})$ measured at the five sites are depicted in Fig. 5. They are sorted according to their origin: maritime, continental/background and pollution influenced. These average humidograms show the high variability in curve shape, hysteresis behavior and magnitude. The particles' deliquescence is seen for the unperturbed sea salt periods (Fig. 5a), in a separation of certain curves (e.g. MHD: green curve and CAB: blue curve) or in a steep increase at $\mathrm{RH} \approx 70 \%$ (for NYA: red curve), while the efflorescence cannot be observed due to the limitations of the dryer (see above). The individual humidograms are separately shown again in Sect. 6.4 (Figs. 8 and 9) with a comparison with model data. (a)

(b)

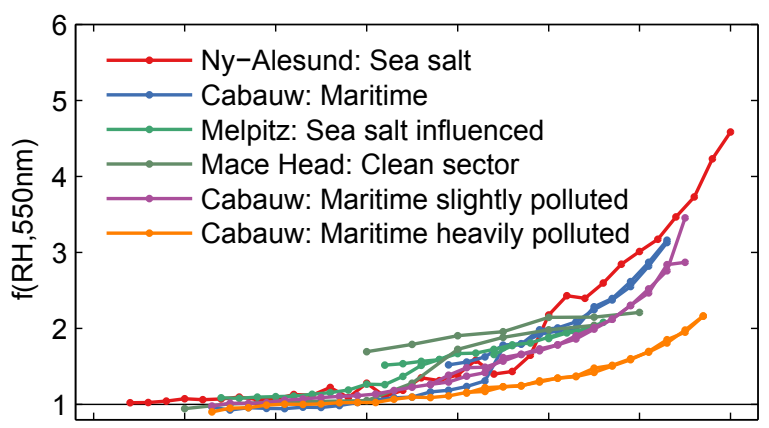

(c)
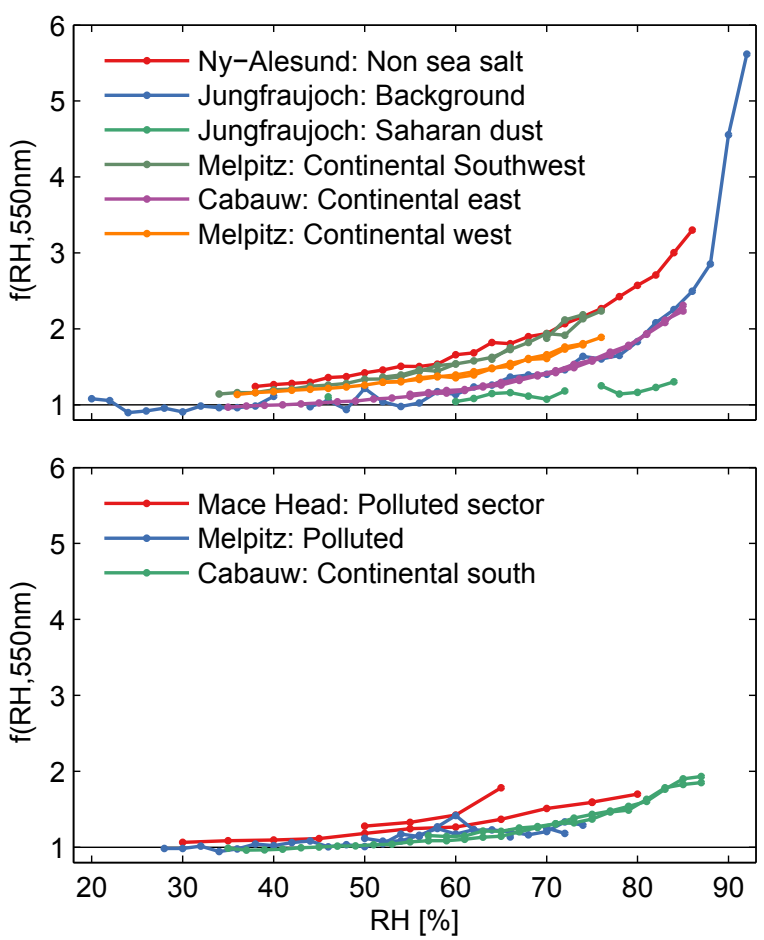

Fig. 5. Example humidograms of $f(\mathrm{RH})$ at $\lambda=550 \mathrm{~nm}$ from the different sites with respect to different air masses: (a) maritime, (b) continental and background, and (c) pollution influenced.

\subsection{Closure studies}

As mentioned in Sect. 5, all closure studies had their individual characteristics due to the site-specific availability of auxiliary aerosol measurements and different instrumentations (see Table 1). The optical properties were calculated using Mie theory (see Sect. 4). Figure 6 shows the ratios of the predicted to the measured values of $f(\mathrm{RH})$ as probability density functions for the five sites. An optical closure with respect to the intensive parameter $f(\mathrm{RH})$ was achieved at all five sites (on average better than $10 \%$, see details below), again increasing confidence in the performed in situ measurements. It should be mentioned that the optical closure with respect to the dry and wet scattering coefficients (the extensive variables) was a prerequisite for the calculation of $f(\mathrm{RH})$, and was achieved at all sites as well (see individual 

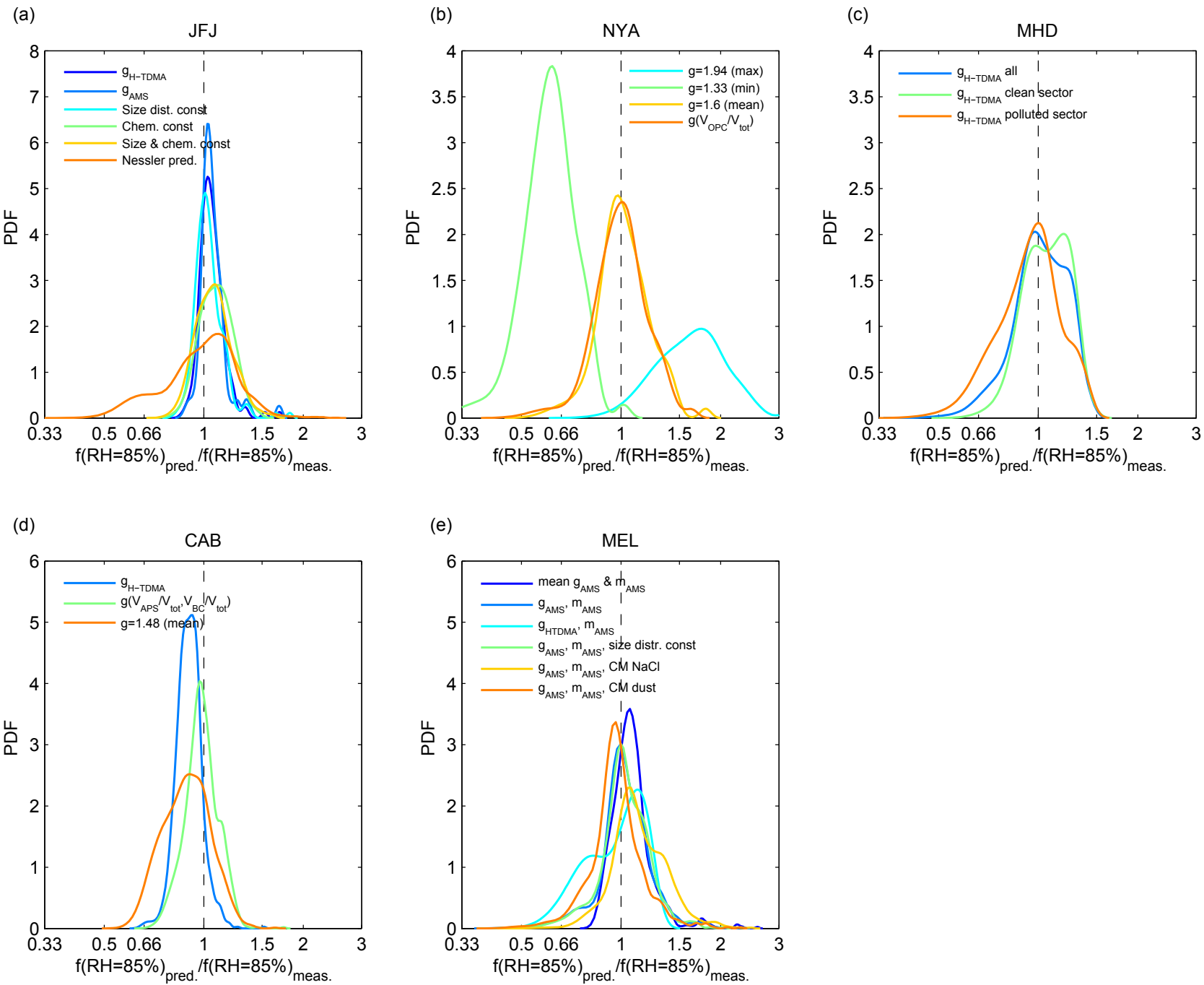

Fig. 6. Probability density function (PDF) of predicted to measured $f(\mathrm{RH}=85 \%, 550 \mathrm{~nm})$ of the individual closure studies, which were characterized by their own specific settings (see text). $g_{\text {HTDMA }}$ denotes the hygroscopic growth factor measured by the H-TDMA, while $g_{\mathrm{AMS}}$ is the calculated value from the chemical composition measurement of AMS and aethalometer or MAAP instrument. $g\left(V_{\mathrm{OPC}} / V_{\text {tot }}\right)$ shows the result for a site-specific parameterization derived for Ny-Ålesund (NYA; see Zieger et al., 2010), while $g\left(V_{\text {APS }} / V_{\text {tot }}, V_{\text {APS }} / V_{\text {tot }}\right)$ is a site-specific parameterization for Cabauw (CAB; see Zieger et al., 2011). $m_{\text {AMS }}$ denotes the particles' complex refractive index derived from AMS and MAAP or aethalometer measurements. CM denotes the coarse mode.

publications mentioned in Table 1). However, the focus is here set on $f(\mathrm{RH})$ our main observational quantity which is an intensive parameter.

At JFJ, the best closure was achieved if the measured size distribution, the chemical composition (refractive index) and the hygroscopic growth factor (calculated from AMS plus aethalometer measurements, or measured by H-TDMA) were used in the Mie model (mean ratio \pm standard deviation: $1.08 \pm 0.13$ using $g_{\text {AMS }}$ and $1.07 \pm 0.12$ using $g_{\text {HTDMA }}$ ). The slightly higher predicted values were probably due to calibration issues of the RH sensor inside the WetNeph. Keeping the chemical composition (refractive index and hygroscopic growth) or the size distribution shape, or both constant still delivered reasonable prediction results $(1.06 \pm 0.14$,
$1.11 \pm 0.12$, and $1.11 \pm 0.14$, respectively), showing that a mean chemical composition is sufficient to predict $f(\mathrm{RH})$. This result is in accordance with findings of Jurányi et al. (2010) who showed that for a prediction of the cloud condensation nuclei (CCN) number concentration at JFJ, using measured size distribution and hygroscopicity measurements $(\mathrm{H}-$ TDMA), and a mean submicron chemical composition is sufficient. Nessler et al. (2005a) proposed a simplified scheme to predict $f(\mathrm{RH})$ for the summer and winter periods separately, using the measured Angström exponent of the dry scattering coefficient. A slight overestimation with a broader distribution of the PDF of the predicted to measured value of $f(\mathrm{RH}=85 \%)$ is observed due to the simplifications in this model $(1.07 \pm 0.27$, see orange curve in Fig. 6a). This 
model is based on the fact that the aerosol coarse mode at JFJ consists mainly of non-hygroscopic mineral dust which is characterized by low Angström exponents, in contrast to the other four sites where the coarse mode was mainly attributed to sea salt. However, a full seasonal comparison of the model by Nessler et al. (2005a) would be desirable.

At NYA, the measured values of $f(\mathrm{RH}=85 \%)$ were in general higher than those measured at other sites (see Fig. 4). The full chemical composition and the hygroscopic growth were not measured directly. Nevertheless, the hygroscopic growth was retrieved from the measured size distribution and the wet and dry scattering properties using Mie theory and by assuming internally mixed spherical particles with a fixed refractive index (ammonium sulfate). The hygroscopic growth factor, one input of the Mie calculations, was varied until it matched the measured $f(\mathrm{RH})$ values (see Zieger et al., 2010, for more details). The refractive index was found to be of minor influence in the $g(\mathrm{RH})$-retrieval; a relative change of $10 \%$ only caused a relative difference of less than $5 \%$ in the retrieved $g(\mathrm{RH})$-values. As summarized in Fig. 6b, a mean hygroscopicity (using a growth factor of $g(\mathrm{RH}=85 \%)=1.6)$ is also sufficient to predict $f(\mathrm{RH}=85 \%)$ at NYA (mean ratio \pm standard deviation: $1.07 \pm 0.2$ ), although with a higher uncertainty than that at JFJ. Although a mean $g(\mathrm{RH})$ was relatively sufficient for the prediction, it can also lead to large uncertainties in the predicted $f(\mathrm{RH})$, as can be seen in Fig. 6b, where the upper and lower bound of the retrieved $g(\mathrm{RH})$ was used as a constant value for the entire time series $(1.78 \pm 0.41$ and $0.64 \pm 0.11$, respectively). A parameterization of $g(\mathrm{RH})$ using the measured volume coarse mode fraction (discussed in Zieger et al. (2010)), brought only a slight improvement $(1.05 \pm 0.19)$.

At MHD (Fig. 6c), the calculations were performed assuming a different refractive index for the polluted (higher imaginary part) and clean sector (Fierz-Schmidhauser et al., $2010 \mathrm{~b})$. The $g(\mathrm{RH})$ of the H-TDMA was only available at $D_{\text {dry }}=165 \mathrm{~nm}$. The closure was achieved for both cases (mean \pm standard deviation for all cases: $1.07 \pm 0.18$; polluted cases: $1.00 \pm 0.20$; clean cases: $1.10 \pm 0.16$ ). For the clean case, the agreement was slightly worse; this was attributed to the assumption of the refractive index and problems with combining the size distribution measurements of coarse and fine mode, which showed discrepancies when comparing the surface size distribution.

For $\mathrm{CAB}$, the situation is more complex, because the aerosol origin showed larger fluctuations (see trajectories in Fig. 3). Besides the continental and urban influence, the nearby marine environment also contributed to the aerosol composition. As described in Zieger et al. (2011), the measured hygroscopic growth factor is limited to smaller size ranges, from a dry diameter of $35 \mathrm{~nm}$ (at CAB), to the largest dry diameter of $165 \mathrm{~nm}$. The larger particles (those above $165 \mathrm{~nm}$ ) were therefore missed by the H-TDMA. Since larger particles can consist of highly hygroscopic sea salt particles, the ratio of predicted to measured values of $f(\mathrm{RH}=85 \%)$ in
Fig. 6d (blue curve) using the growth factor $g(\mathrm{RH})$ of the $\mathrm{H}-$ TDMA is shifted towards an underestimation of the predicted $f(\mathrm{RH}=85 \%)$, with a mean ratio and standard deviation of $0.91 \pm 0.09$. A proposed parameterization of $g(\mathrm{RH})$ using the coarse mode volume fraction and black carbon (BC) volume fraction improved the agreement with the measured values (with $1.00 \pm 0.12$; see green curve in Fig. 6d). An increased $\mathrm{BC}$ volume fraction will tend to decrease $g(\mathrm{RH})$, while an increased coarse mode volume fraction is a sign of more sea salt contribution, which will increase $g(\mathrm{RH})$. Both volume fractions are continuously measured by an OPSS, SMPS and MAAP at that site (see Sect. 3.2). Together with the measured size distributions and an assumption on the refractive index, the $f(\mathrm{RH})$ can then be estimated (for more details see Zieger et al., 2011). Assuming a constant value of $g(\mathrm{RH})$, which can be done, e.g., for JFJ and NYA, gives a less precise prediction at $\mathrm{CAB}$, as can be seen in Fig. 6d (orange curve with a mean ratio of $0.92 \pm 0.15$ ).

Closure was also achieved at MEL (Fig. 6e). Good results were achieved if the refractive index and growth factor were derived from the AMS (plus MAAP) measurements, or if the growth factor was taken from the H-TDMA measurement and the refractive index was derived from AMS and MAAP (mean ratio \pm standard deviation: $1.08 \pm 0.22$ and $1.01 \pm 0.18$, respectively). Both instruments were operated successfully during the entire campaign, while the H-TDMA was only available for part of the time. A mean $g(\mathrm{RH}=90 \%)=1.53$ was found to be sufficient for the prediction at MEL, albeit with exceptions, especially during transported sea salt and high anthropogenic pollution events. In addition, the coarse mode composition was varied for the calculation; if a very hygroscopic coarse mode of $\mathrm{NaCl}$ was assumed, the $f(\mathrm{RH})$ was clearly overpredicted $(1.20 \pm 0.25)$, while an assumed dust coarse mode clearly lead to a good agreement $(1.02 \pm 0.22)$.

Generally, all measurements of $f(\mathrm{RH})$ were predicted on average within $10 \%$, with changing variability among the different sites and assumptions, if the hygroscopic growth factor was measured (or for NYA assumed) correctly. A table summarizing the mean and the standard deviation of the predicted and measured $f(\mathrm{RH}=85 \%)$, plus the mean ratio of predicted to measured value can be found in the Supplement. A general uncertainty analysis for the closure studies was performed using the Monte Carlo Method according to Anderson (1976). It was found that the relative error in the calculated $f(\mathrm{RH})$ increased for larger hygroscopic growth factors, but was always smaller than 15-25\%, despite the high uncertainties assumed, e.g., for the refractive index. More details can be found in Appendix A.

In summary, both size and chemical composition mattered when determining $f(\mathrm{RH})$; this is schematically depicted in Fig. 7. For the aerosol discussed here, the relative contributions of the fine mode and the coarse mode and the specific chemical composition were important. At JFJ, the coarse mode was mainly attributed to long-range 


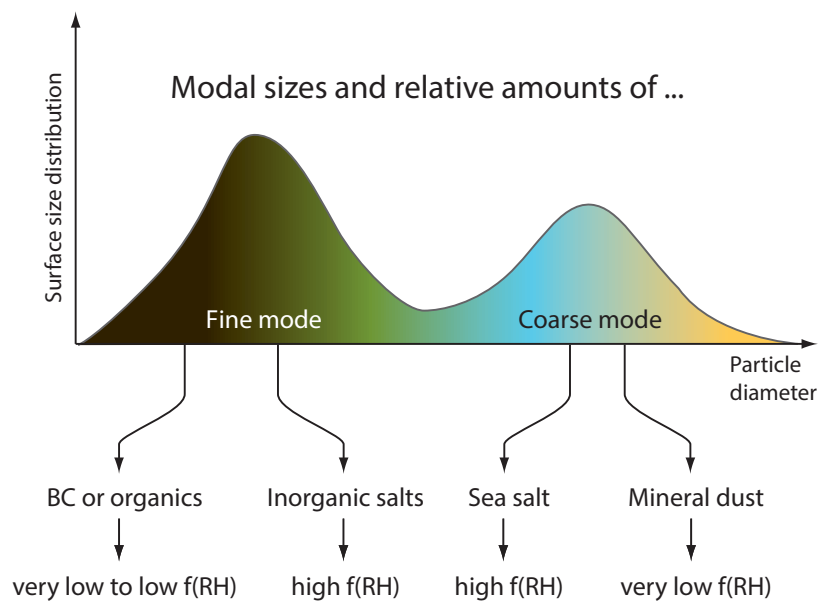

Fig. 7. Schematic overview of the factors influencing the scattering enhancement $f(\mathrm{RH})$. The size and the relative contributions of the different modes with their distinct chemical composition (governing the hygroscopic growth and refractive index) all influence $f(\mathrm{RH})$. This also includes the compensating effects of size and chemical composition.

transported non-hygroscopic mineral dust, whereas at NYA, MEL, MHD, and CAB, the coarse mode was mainly dominated by hygroscopic seas salt. Sea salt was never observed at JFJ, which also explains the absence of hysteresis effects (which were occasionally observed at all other sites). The fine mode was dominated by organic substances with low hygroscopicity, non-hygroscopic BC, or by hygroscopic inorganic salts. As seen in Fig. 2, the interaction between size and hygroscopicity can lead to compensation effects for $f(\mathrm{RH})$, as observed at NYA, where smaller and less hygroscopic particles had the same magnitude of $f(\mathrm{RH})$ as larger and more hygroscopic particles (Zieger et al., 2010).

\subsection{Can a simple analytical method be established for the $f(\mathbf{R H})$-prediction?}

To show the difficulty in retrieving a simple analytical method for an accurate $f(\mathrm{RH})$-prediction, we have performed a sensitivity study by varying the main input parameters of the Mie calculations in the typically encountered ranges. A bimodal lognormal size distribution was assumed

$\frac{\mathrm{d} N_{i}(D)}{\mathrm{d} \log D}=\frac{N_{i}}{\sqrt{2 \pi} \log \sigma_{i}} \exp \left[-\frac{1}{2}\left(\frac{\log D-\log D_{\bmod , i}}{\log \sigma_{i}}\right)^{2}\right]$,

where $D$ denotes the diameter, $D_{\bmod , i}$ is the mode diameter, $N_{i}$ is the total particle number density, and $\sigma_{i}$ is the standard deviation of the distribution of mode $i$ (with $i=1$ as the fine mode (FM) and $i=2$ as the coarse mode (CM)).
The following parameters were varied:

- Fine mode diameter $\left(D_{\text {mod }}^{\mathrm{FM}}\right)$

- Coarse mode number fraction

$\left(\mathrm{CM}\right.$ frac $\left.=N_{\mathrm{CM}} /\left(N_{\mathrm{FM}}+N_{\mathrm{CM}}\right)\right)$

- Fine mode hygroscopicity ( $\kappa_{\mathrm{FM}}$, see Eq. 3)

- Coarse mode hygroscopicity $\left(\kappa_{\mathrm{CM}}\right)$

- Standard deviation of fine mode $(\sigma)$

- Imaginary part of refractive index $\left(m_{\mathrm{imag}}\right)$

The coarse mode diameter was assumed to be constant at $D=2 \mu \mathrm{m}$. The real part of the refractive index was assumed to be $m=1.54$, when the calculations were performed for $\lambda=550 \mathrm{~nm}$ and $\mathrm{RH}=85 \%$.

The result for a constant refractive index $(m=1.54)$ and a standard deviation of $\sigma=1.8$ for coarse and fine mode is shown in Table 3 for four different coarse mode number fractions $(\mathrm{CM}$ frac $=0.02,0.01,0.00001,0)$ and alternatively for a very hygroscopic $\left(\kappa_{\mathrm{CM}}=1\right.$, e.g. sea salt) or non-hygroscopic $\left(\kappa_{\mathrm{CM}}=0\right.$, e.g. mineral dust) coarse mode. The hygroscopicity of the fine mode is also varied $\left(\kappa_{\mathrm{FM}}=0\right.$, $0.25,0.75,1)$. The figures of the entire sensitivity study can be found in the Supplement.

The strong influence of small amounts of coarse mode particles on the overall $f(\mathrm{RH})$ can be seen. Coarse mode particles can suppress $f(\mathrm{RH})$ in case of dust particles, or enhance the overall $f(\mathrm{RH})$ in case of very hygroscopic particles (e.g. pure $\mathrm{NaCl}$ ). The mode diameter of the fine mode (in Table 3, exemplary at 50, 100 and $250 \mathrm{~nm}$ ) determines if the mode is moving into the optically relevant size range at enhanced RH (here $85 \%$ ). This separate growth into the optical active size range also explains the wave-like structures seen in Figs. S1 and S2 of the Supplement. With the complete absence of coarse mode particles, the $f(\mathrm{RH})$ values can reach high values similar to those seen in the calculation of the monodisperse substances shown in Fig. 2.

The dependence of $f(\mathrm{RH})$ on the standard deviation of the fine mode $(\sigma)$ and the imaginary part has been investigated as well (see Fig. S2 in the Supplement). The dependence of $f(\mathrm{RH})$ on a varying $\sigma$ or imaginary part of $m$ is less pronounced than the parameters discussed above. The strong influence of the coarse mode number fraction is seen in a similar way as in Table 3.

This exercise demonstrates a high dependency of $f(\mathrm{RH})$ on the different size and hygroscopicity parameters. It also shows that a simple analytical method of determining $f(\mathrm{RH})$ for all important aerosol types cannot be created without knowledge of further constraints like the mean fine mode diameter, or the composition of the coarse mode. For sites with low variation of the aerosol microphysical properties, a site-specific proxy can be used to predict $f(\mathrm{RH})$; the same proxy would fail for another site. As an example, at JFJ, 
Table 3. The scattering enhancement $f(\mathrm{RH})$ at $\mathrm{RH}=85 \%$ and $\lambda=550 \mathrm{~nm}$ modeled for different fine mode diameters $\left(D_{\mathrm{FM}}\right)$ and fine mode hygroscopicities $\left(\kappa_{\mathrm{FM}}\right)$. The coarse mode was assumed to consist of non-hygroscopic material $\left(\kappa_{\mathrm{CM}}=0\right.$, e.g., dust, middle column $)$ or of very hygroscopic material $\left(\kappa_{\mathrm{CM}}=1\right.$, e.g., sea salt, right column). $\mathrm{CM}$ frac denotes the coarse mode number fraction. The refractive index was assumed to be constant with $m=1.54$. See text for more details.

\begin{tabular}{cccccccccc}
\hline & & \multicolumn{4}{c}{$f(\mathrm{RH}=85 \%, 550 \mathrm{~nm})$ with } & \multicolumn{3}{c}{$f(\mathrm{RH}=85 \%, 550 \mathrm{~nm})$ with } \\
& \multicolumn{4}{c}{$\kappa_{\mathrm{CM}}=0$ and CM frac $=$} & \multicolumn{3}{c}{$\kappa_{\mathrm{CM}}=1$ and CM frac $=$} \\
$D_{\mathrm{FM}}$ & $\kappa_{\mathrm{FM}}$ & 0.02 & 0.01 & $10^{-5}$ & 0 & 0.02 & 0.01 & $10^{-5}$ & 0 \\
\hline 50 & 0 & 1 & 1 & 1 & 1 & 3.38 & 3.37 & 1.35 & 1 \\
50 & 0.25 & 1 & 1.01 & 2.13 & 2.33 & 3.38 & 3.38 & 2.49 & 2.33 \\
50 & 0.5 & 1.01 & 1.02 & 3.48 & 3.92 & 3.38 & 3.39 & 3.84 & 3.92 \\
50 & 1 & 1.02 & 1.04 & 6.62 & 7.6 & 3.4 & 3.41 & 6.97 & 7.6 \\
\hline 100 & 0 & 1 & 1 & 1 & 1 & 3.26 & 3.15 & 1.02 & 1 \\
100 & 0.25 & 1.05 & 1.1 & 1.99 & 2 & 3.31 & 3.25 & 2.01 & 2 \\
100 & 0.5 & 1.11 & 1.21 & 3.05 & 3.07 & 3.37 & 3.35 & 3.07 & 3.07 \\
100 & 1 & 1.22 & 1.43 & 5.23 & 5.27 & 3.48 & 3.57 & 5.25 & 5.27 \\
\hline 250 & 0 & 1 & 1 & 1 & 1 & 2.21 & 1.81 & 1 & 1 \\
250 & 0.25 & 1.39 & 1.52 & 1.79 & 1.79 & 2.6 & 2.33 & 1.79 & 1.79 \\
250 & 0.5 & 1.72 & 1.98 & 2.48 & 2.48 & 2.94 & 2.78 & 2.48 & 2.48 \\
250 & 1 & 2.3 & 2.75 & 3.64 & 3.64 & 3.51 & 3.56 & 3.64 & 3.64 \\
\hline
\end{tabular}

the Ångström exponent of particle scattering coefficient (as a proxy for the mean size) can be used to estimate $f(\mathrm{RH})$ (Nessler et al., 2005a). This proxy is only applicable because the coarse mode at JFJ predominantly consists of (nonhygroscopic) mineral dust. The same proxy would fail for sites with sea salt influence, where the coarse mode would be dominated by hygroscopic substances. A reliable prediction of $f(\mathrm{RH})$ will therefore always need a full determination of the particle number distribution (fine and coarse mode) and information on the hygroscopicity and/or main chemical composition.

\subsection{Comparison to OPAC}

The measured scattering enhancement factors were compared to the database OPAC (optical properties of aerosol and clouds) by Hess et al. (1998). OPAC is a popular database on aerosol and cloud optical properties that is widely used by the scientific community ${ }^{1}$ since it provides a comprehensive set of microphysical and optical data of aerosols and clouds. It is closely linked to the Global Aerosol Data Set (GADS) by Köpke et al. (1997). The data are stored as components that are meant to be representative for a certain origin (Hess et al., 1998). All components represent average conditions and the authors clearly state that the given values may not necessarily be valid for actual conditions. Nevertheless, a comparison between the measurements performed here and OPAC is undertaken as a first step in improving future versions of OPAC.

The main OPAC aerosol components will be briefly described here in the following. The water-soluble component

\footnotetext{
${ }^{1}$ ISI Web of Knowledge lists over 880 citations (last access: 8 March 2013).
}

combines all aerosol particles that originate in gas to particle conversion (including various kinds of sulfates, nitrates, and also organic substances), while the insoluble component describes soil particles that also contain organic compounds, but do not experience hygroscopic growth. The soot component describes the absorbing black carbon. The sea salt components are given for the accumulation $(100 \mathrm{~nm}<D<1 \mu \mathrm{m})$ and the coarse $(D>1 \mu \mathrm{m})$ mode separately and both are dependent on RH. To describe desert aerosols that originated in the desert, different mineral components are provided. A special mineral-transported component is used to describe long-range transported mineral dust. The sulfate component is mainly used to describe the high-sulfate containing Antarctic aerosol, and is also used to model the stratospheric background aerosol. It is composed of $75 \% \mathrm{H}_{2} \mathrm{SO}_{4}$ and is able to take up water, and therefore depends on $\mathrm{RH}$.

Besides the wavelength dependent refractive index, the number size distribution of each component is provided as a lognormal size distribution (see Eq. 7). The size parameters and refractive indexes are provided for eight different RHs $(0 \%, 50 \%, 70 \%, 80 \%, 90 \%, 95 \%, 98 \%$, and $99 \%)$ for the RH-dependent components. The OPAC components can be externally mixed (using the number mixing ratio of each component) to different aerosol types. Hess et al. (1998) propose aerosol types (ready mixtures) as examples of those typically found in the atmosphere.

The strength of OPAC is the option it gives to individually compose aerosol types (using the number mixing ratio, as mentioned above). Therefore, our measurements will also be compared to individually mixed aerosol types in addition to the aerosol examples that are proposed in OPAC. These mixtures were calculated when full size distribution 

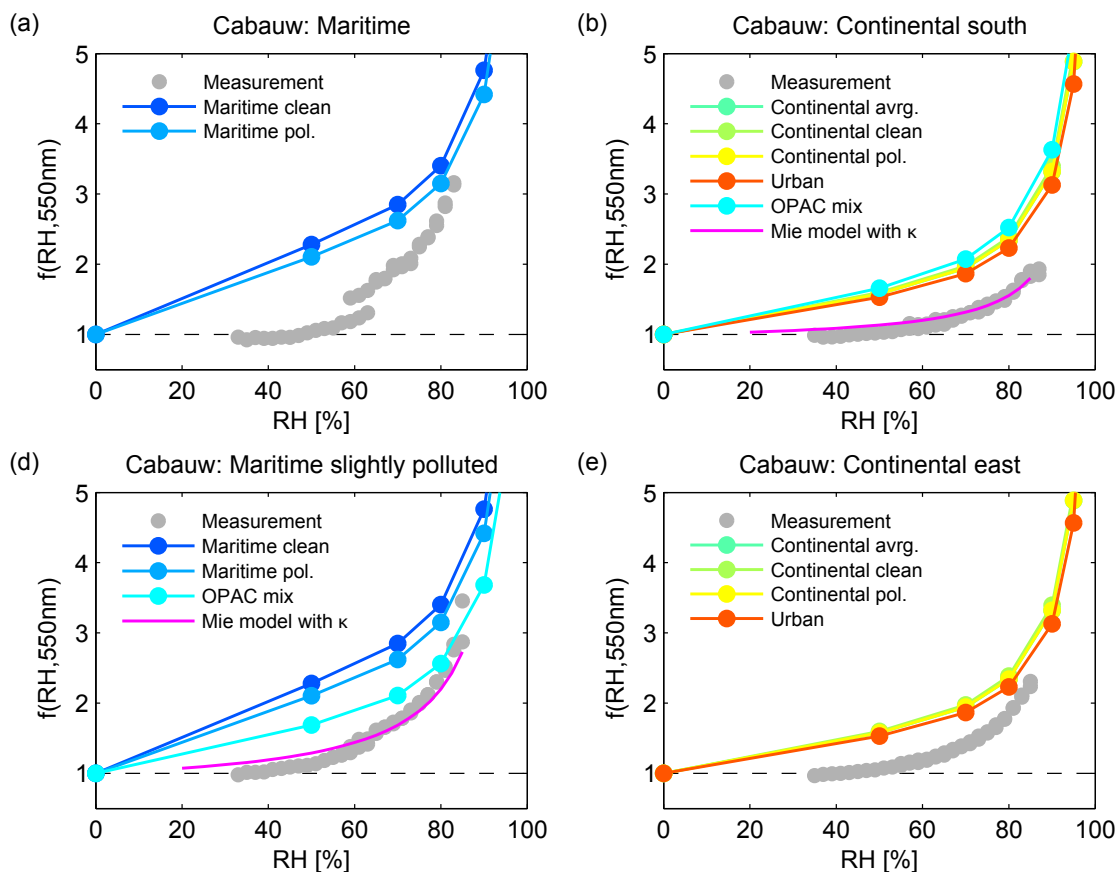

(e)

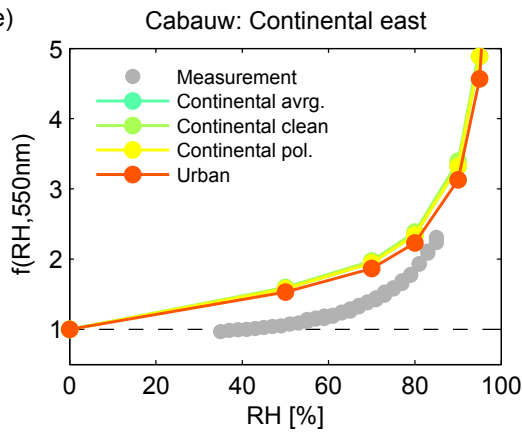

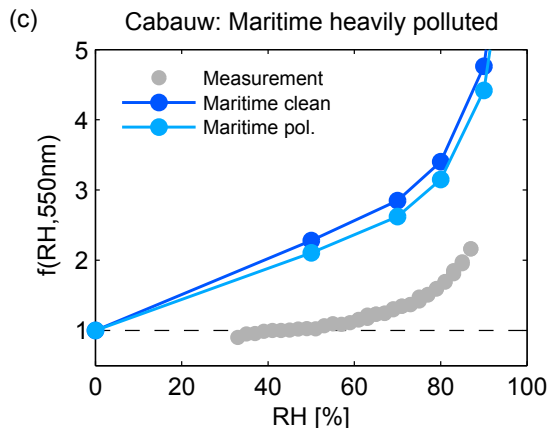

(f)

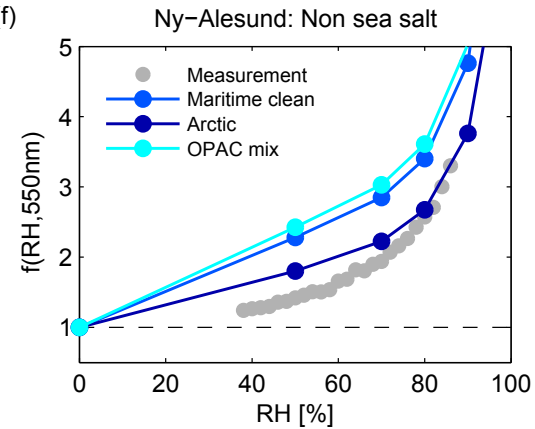

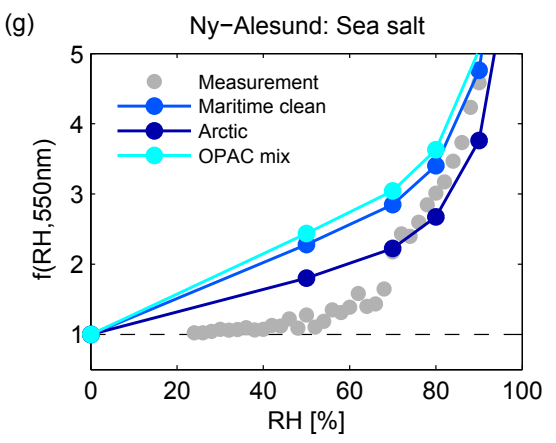

Fig. 8. Example humidograms from the investigated sites (gray bullets) compared to OPAC aerosol examples given in Hess et al. (1998) (colored bullet lines). The cyan bullets (OPAC mix) denote the OPAC result if the individual OPAC components are weighted with the measured size distribution. The magenta line shows the calculated humidogram using the measured size distribution, the (partially) measured chemical composition, the hygroscopicity parameter $\kappa$, and Mie calculations if the measurements were available (see text for details).

measurements were available at the same time. The number mixing ratio $n_{i}$ for each component was calculated as follows:

$n_{i}=\frac{N_{i}}{N_{\text {tot }}}=\left(\int_{D_{i, \text { min }}}^{D_{i, \text { max }}} \frac{\mathrm{d} N(D)}{\mathrm{d} \log D} \mathrm{~d} \log D\right) / N_{\mathrm{tot}}$,

where $N_{i}$ is the number concentration between $D_{i, \min }$ and $D_{i, \max }$, which is determined by taking the middle value of $D$ between the individual mode diameters of two neighboring components, and $N_{\text {tot }}$ is the total number concentration. For a mixture of water-soluble and sea salt (acc. mode) components, for example, the size distribution would be integrated from 0 to $187.8 \mathrm{~nm}$ to calculate the apparent number concentration of the water-soluble component and from $187.8 \mathrm{~nm}$ to the end of the measured distribution for the number con- centration of the sea salt (acc. mode) component. For CAB, the mixture was composed with the soot, the water-soluble, and the two sea salt components. For NYA, the water-soluble and the two sea salt components were chosen, while for JFJ only the water-soluble and the mineral-transported components were used for the calculation of $f(\mathrm{RH})$.

Figures 8 and 9 show example humidograms recorded at the five sites (grey points) compared to the OPAC example aerosol types that would have been expected to be observed at the specific site. The individually mixed OPAC results are shown (called OPAC mix in Figs. 8 and 9) for time periods when corresponding size distribution measurements were available. For the same periods, the result of the Mie model calculations has been added (magenta line in Figs. 8 and 9), which used the measured (or for NYA retrieved) $\kappa$-value (see Eq. 3) and the measured particle number size distribution as input. Humidograms without a magenta curve 

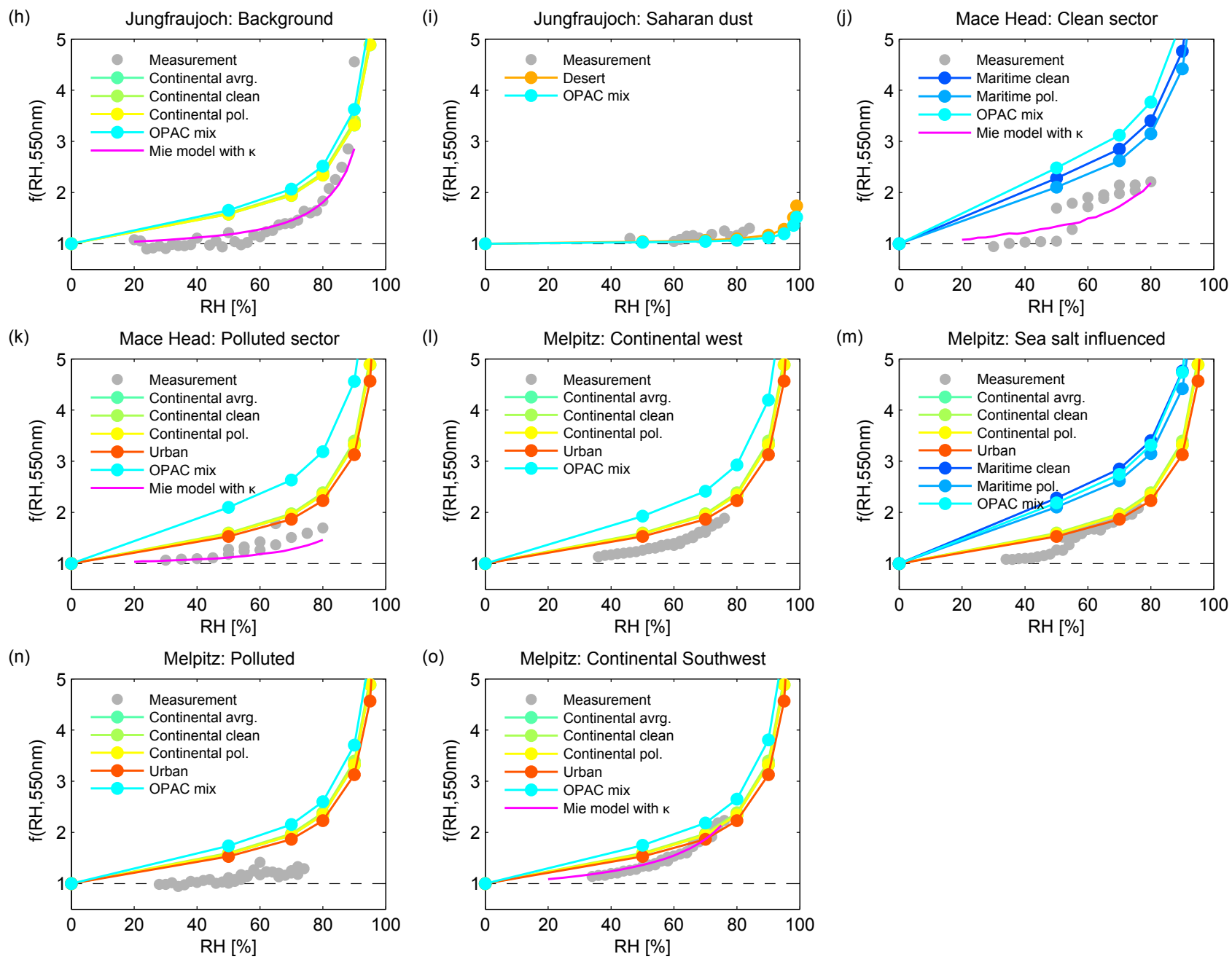

Fig. 9. Same as Fig. 8, but for the other sites.

(in Figs. 8 and 9) therefore had no parallel hygroscopicity or particle number size distribution measurements.

In general, Figs. 8 and 9 reveal that the calculated values using the OPAC input data, which are only given for eight discrete RH values, are clearly higher than the measured values of $f(\mathrm{RH})$ for all five sites; the one exception is the Saharan dust event at JFJ, which is well described by OPAC (see Fig. 9i). OPAC is not able to describe hysteresis effects observed, e.g. for clean maritime air (see Fig. 8a and g) and only refers to the deliquesced state (as does the $\kappa$-equation).

The shape also significantly differs from the measurements, especially for low and medium values of RH. Taking the measured number size distribution with re-mixed OPAC components does not improve the agreement significantly, except in the case of $\mathrm{CAB}$ maritime slightly polluted air masses (Fig. 8d). The calculated $f(\mathrm{RH})$ curve using the measured (or retrieved) $\kappa$-value seems to perform well, indicating that the $\kappa$-equation (Eq. 3 ) is suitable to describe the curvature of $f(\mathrm{RH})$ in combination with Mie calculations.
The overestimation by OPAC could be explained by:

a. the implemented hygroscopic growth

b. the fixed size distribution modes

c. the used refractive indices

of the individual components. The influence of the refractive index cannot be checked due to missing chemical composition measurements, while the influence of the implemented size distributions and the hygroscopic growth can be tested against the measurements when they are available (see below).

The water-soluble and soot components are the two main components that describe the fine mode in OPAC besides sea salt (acc. mode). The OPAC aerosol type surface size distributions are compared to the measured ones in Fig. 10a-f. The number size distributions have been transferred to (normalized) surface size distributions, since they are a better representation of the optically relevant size ranges. For the proposed aerosol type examples, the surface size distributions 

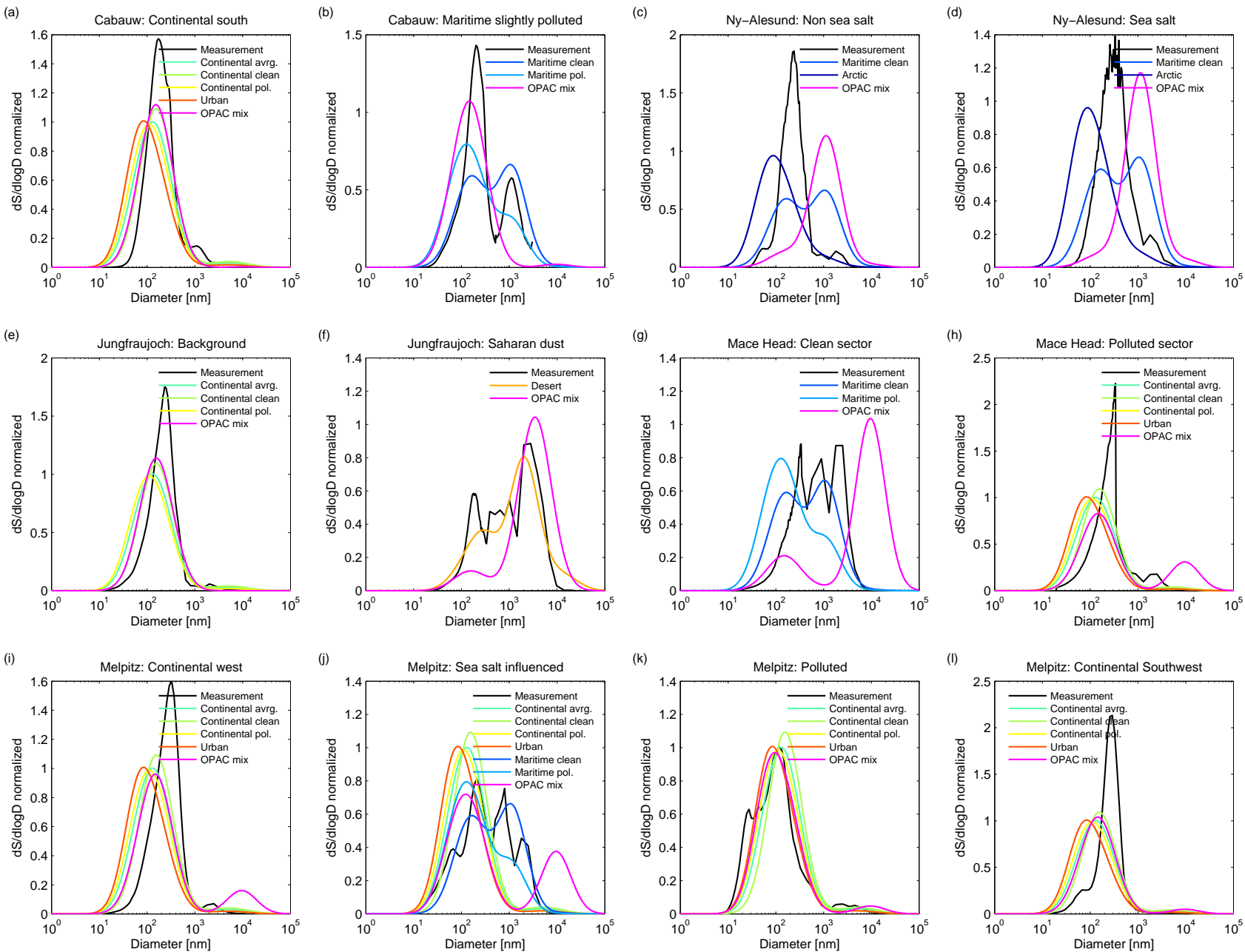

Fig. 10. (a-f) Normalized surface size distributions (black line) measured during the humidograph mode periods as shown in Figs. 8 and 9 , normalized surface size distributions from the OPAC aerosol type examples (colored lines), and the OPAC size distributions if the individual components are weighted with the measured number size distribution (magenta line). Note that the OPAC components have a fixed mode diameter and therefore the OPAC individually mixed size distributions do not match the measured distribution in all cases.

are mainly shifted to smaller diameters and are also characterized by larger mode standard deviations compared to the measured distributions. The concentration (or particle surface) is different than the measurements as well. Mixing the components according to the measured number size distribution (using Eq. (8), as described above) does not improve the comparison, since the fixed distribution modes and standard deviations make accurate mixing difficult (see magenta line in Fig. 10a-f).

According to Hess et al. (1998), the hygroscopic growth factor $g(\mathrm{RH})$ in OPAC is based on the work of Hänel and Zankl (1979) and is shown in Fig. 11 for the four RHdependent OPAC components (red bullets). However, they differ from the original data of Hänel and Zankl (1979) (R. Dlugi, personal communication, 2013, which are shown as blue crosses in Fig. 11). Therefore, an erroneous implementation of the hygroscopic growth within OPAC could be a major reason of the found differences. In addition, Fig. 11 shows the $g(\mathrm{RH})$ calculated using the $\kappa$-equation (see Eq. 3). For the sea salt components $g(\mathrm{RH}=90 \%)=2.1$ was taken from Swietlicki et al. (2008) for highly hygroscopic marine aerosol. For the water-soluble component a mean value of $g(\mathrm{RH}=90 \%)=1.48$ measured by the H-TDMA during the Cabauw campaign was taken, while, for the sulfate droplets, $g(\mathrm{RH}=90 \%)=2.05$ was taken from Topping et al. (2005). The implemented hygroscopic growth in OPAC does not correspond with the course of $g(\mathrm{RH})$ if the $\kappa$-equation is taken into account. Especially for low RH $(<80 \%)$ the OPAC values are clearly above the $\kappa$-curve, while for higher RH the agreement seems to be better. As shown in the example humidograms (see Figs. 8 and 9), the $\kappa$-equation is a good approximation of the hygroscopic growth in terms of $f(\mathrm{RH})$ at different RH in combination with the measured size distribution, an appropriate refractive index, and Mie theory. 
Table 4. Original and modified hygroscopic growth factor $g(\mathrm{RH})$ of the RH-dependent OPAC components (Hess et al., 1998). The modified values of $g(\mathrm{RH})$ for the sea salt component were taken from Swietlicki et al. (2008), those for the water soluble from Zieger et al. (2011) and those for the sulfate component from Topping et al. (2005). The modified values were calculated for the corresponding relative humidities (RH) using Eq. (3). See text and Fig. 11 for more details.

\begin{tabular}{ccccccccc}
\hline \multirow{2}{*}{ RH $(\%)$} & \multicolumn{2}{c}{ Sea salt (coa. mode) } & \multicolumn{2}{c}{ Sea salt (acc. mode) } & \multicolumn{2}{c}{ Water soluble } & \multicolumn{2}{c}{ Sulfate droplets } \\
Original & Modified & Original & Modified & Original & Modified & Original & Modified \\
\hline 50 & 1.61 & 1.24 & 1.61 & 1.24 & 1.24 & 1.08 & 1.41 & 1.22 \\
70 & 1.81 & 1.46 & 1.81 & 1.46 & 1.34 & 1.17 & 1.57 & 1.42 \\
80 & 1.99 & 1.67 & 1.99 & 1.67 & 1.44 & 1.26 & 1.70 & 1.62 \\
90 & 2.39 & 2.10 & 2.38 & 2.10 & 1.64 & 1.48 & 1.94 & 2.02 \\
95 & 2.92 & 2.64 & 2.89 & 2.64 & 1.88 & 1.79 & 2.27 & 2.53 \\
98 & 3.91 & 3.58 & 3.83 & 3.58 & 2.25 & 2.36 & 2.81 & 3.43 \\
99 & 4.91 & 4.51 & 4.76 & 4.51 & 2.52 & 2.95 & 3.32 & 4.32 \\
\hline
\end{tabular}

However, it is not suitable to describe the hysteresis effect of aerosol humidification.

To further investigate the influence of the hygroscopic growth as implemented in OPAC, the hygroscopic growth of the water-soluble and sea salt (acc. and coarse mode) was modified and tested against measurements at $\mathrm{CAB}$, where the most reliable $g(\mathrm{RH})$ measurements were obtained. For the modification part, the hygroscopic growth of the watersoluble and the sea salt (acc. and coarse mode) components was changed. The mean $g(\mathrm{RH}=90 \%)=1.48$ measured during the $\mathrm{CAB}$ campaign at $165 \mathrm{~nm}$ was taken for the watersoluble component, and $g(\mathrm{RH}=90 \%)=2.1$ was taken for the two sea salt components from Swietlicki et al. (2008). The $\kappa$-equation was again used to calculate $g(\mathrm{RH})$ at different $\mathrm{RH}$ values (see violet curve in Fig. 11a-c for the applied growth factors). The original and modified $g(\mathrm{RH})$-values are shown in Table 4 for the relative humidities used in OPAC. The time period of the closure study during the CAB campaign was chosen (4-18 July 2009), which is considered to be the most complete time series covering a wide range of different aerosol types, ranging from continental to maritime aerosol types. The number mixing ratios (or number concentrations) of both modes were again calculated using Eq. (8). The soot, water-soluble, and sea salt (acc. mode and coarse mode) components were found to be the most dominant components during the period of the $\mathrm{CAB}$ closure study.

Taking the original components soot, water-soluble, and sea salt (acc. and coarse mode), OPAC overestimates $f(\mathrm{RH})$ especially for the low and medium RH values (as already seen in the example humidograms in Figs. 8 and 9 and as shown in Fig. 12a, where the ratio of calculated to measured value is seen for the above-mentioned closure period at $\mathrm{CAB}$ ). It improves for higher $\mathrm{RH}$, but the ratio is still above 1 at $90 \%$ RH. Modifying the water-soluble and sea salt (acc. and coarse mode) components with hygroscopic growth factors based on the current literature leads to an improved agreement between calculated and observed $f(\mathrm{RH})$ (see Fig. 12b). The remaining discrepancy is probably caused by the fixed distribution modes and in general by the simpli- fication of the aerosol at $\mathrm{CAB}$ when only four main components are assumed. As a first step in improving the OPAC components, we propose using the modified $g(\mathrm{RH})$-values (see Table 4). Equations (5) and (6) can then be used to obtain the wet size distribution and wet refractive index together with the original OPAC component values given at $\mathrm{RH}=0 \%$. Values at other $\mathrm{RH}$ values can be calculated using Eq. (3). This has to be followed by a re-calculation of the optical properties, e.g., by using Mie theory (Bohren and Huffman, 2004).

\section{Recommendations}

The following recommendations concerning a precise measurement and prediction of $f(\mathrm{RH})$ can be derived from this study:

- For a precise measurement of $f(\mathrm{RH})$, a humidified nephelometer should be used. Standard nephelometer truncation and illumination correction should be applied (Anderson et al., 1996). Of crucial importance are a good temperature control and knowledge of the exact RH inside the nephelometer cell. The RH sensors and the entire system should therefore be calibrated using standard salt solutions and monodisperse salt measurements and Mie theory (Fierz-Schmidhauser et al., 2010c).

- If no direct measurements of $f(\mathrm{RH})$ are available, $f(\mathrm{RH})$ can be approximated using the measured particle number size distribution, the hygroscopic growth factor and chemical composition measurements and Mie theory. The $\kappa$-equation (Eq. 3) should be used to describe the RH dependency of $g(\mathrm{RH})$ for the deliquescent aerosol (for the RH range of 50 to $95 \%$ ). However, the user should be aware that the hygroscopic growth measurements with a standard $\mathrm{H}-$ TDMA may miss the important coarse mode contribution to $f(\mathrm{RH})$ and therefore may under- or 
(a)

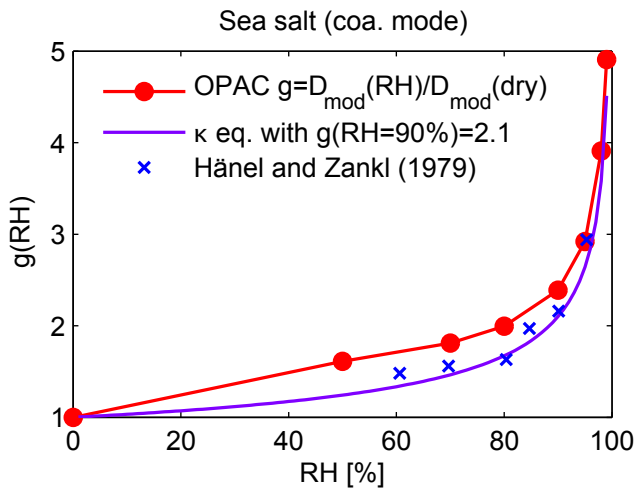

(c)

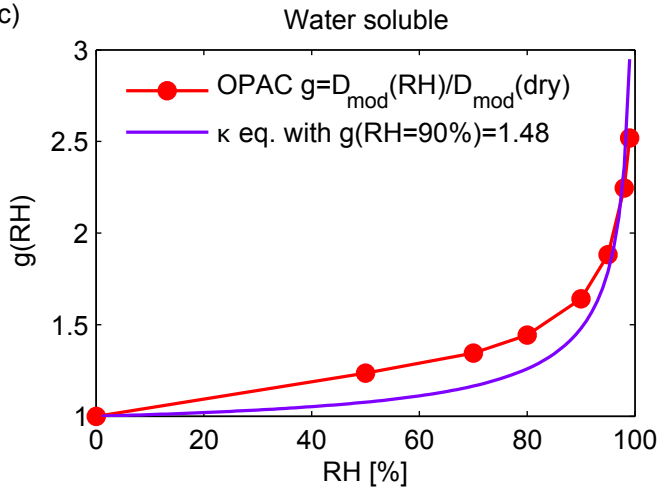

(b)

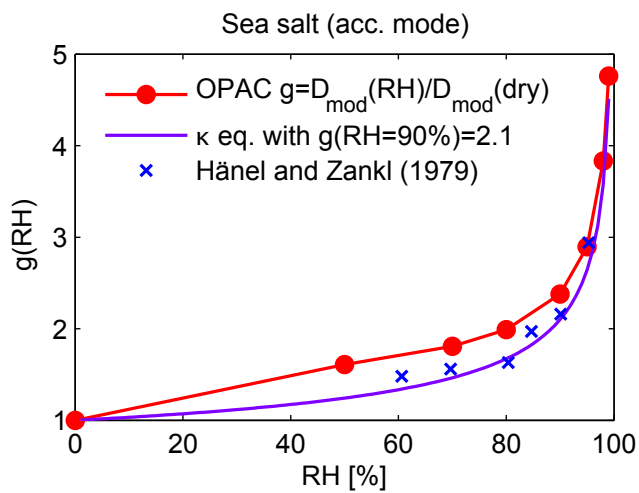

(d)

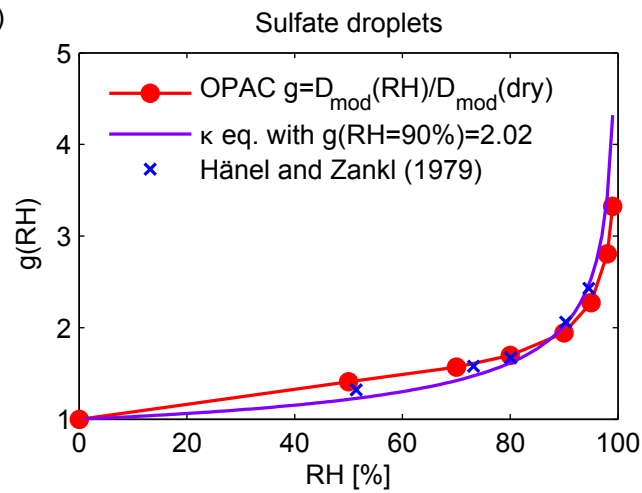

Fig. 11. Hygroscopic growth factor $g(\mathrm{RH})$ as implemented for the four hygroscopic OPAC components. (a) Sea salt (accumulation mode), (b) sea salt (coarse mode), (c) water-soluble, (d) sulfate droplets (used to model Antarctic and stratospheric background aerosol). The mode diameter (red curve) growth factors used for the individual lognormal size distributions are shown. The violet curve denotes the hygroscopic growth factor as calculated using values of $g(\mathrm{RH})$ from the literature and the $\kappa$-equation (see text for details). The blue crosses show the original $g(\mathrm{RH})$ from Hänel and Zankl (1979).
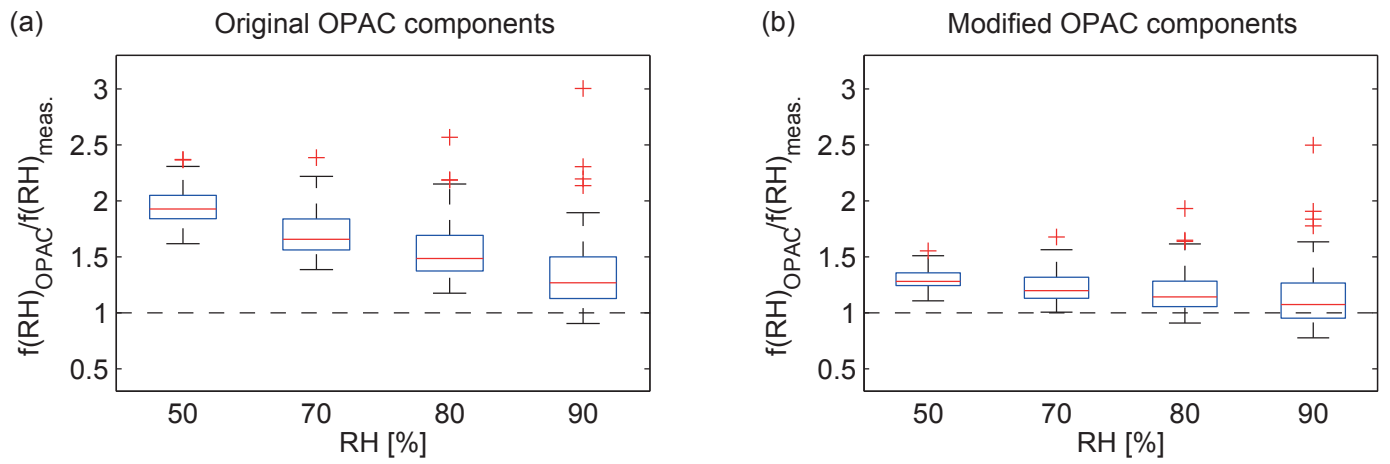

Fig. 12. Box plots of the ratio of calculated to measured $f(\mathrm{RH})$ (at $550 \mathrm{~nm}$ ) for the RH values of 50, 70, 80, and $90 \%$ (OPAC values and range of measurements) for Cabauw (4-18 July 2009). The central red mark is the median, the edges of the box are the 25th and 75th percentiles, the error bars show the extent of the most extreme data points that are not considered outliers, while the outliers are plotted individually (red crosses). (a) $f(\mathrm{RH})$ calculated using the original OPAC components weighted with the measured size distribution. (b) $f(\mathrm{RH})$ calculated using the modified OPAC components (changed hygroscopic growth) weighted with the measured size distribution. 
overestimate the overall $f(\mathrm{RH})$ (see Table 3 but also Fig. 6 in Zieger et al., 2011).

- The humidograph mode should be used to identify hysteresis behavior and thus can be used to further identify air mass origin (e.g. sea salt).

- Optical closure studies should be performed to identify measurement errors and possible model weaknesses, and to constrain the obtained measurement results.

- The components of hygroscopic growth within the OPAC (Hess et al., 1998) should be replaced by values from the current literature (see Table 4). The RH dependency of $g(\mathrm{RH})$ can be approximated for the upper branch using the $\kappa$-equation (Eq. 3).

\section{Conclusions}

The effect of hygroscopic growth on aerosol particle light scattering has been investigated at five European sites using measurements and model calculations. Each site has been chosen because it is representative for certain aerosol types. A high spatial and temporal variability of $f(\mathrm{RH})$ has been observed throughout Europe, starting from low values for long-range transported mineral dust to intermediate values for continental aerosol to high values for pristine maritime or Arctic aerosol. Hysteresis was observed when pure sea salt was present. Compensating effects between size and hygroscopicity were observed in the Arctic. The variability and complexity of aerosol composition increased from remote sites to urban and continental sites, and therefore the number of known parameters needed to predict $f(\mathrm{RH})$ increased concurrently. Free tropospheric aerosol found, e.g., at the Jungfraujoch, can be simply parameterized using the Ångström exponent (Nessler et al., 2005b). This rather simplistic approach can only be taken at this site due to that fact that increased coarse mode fractions (low Ångström exponents) at the Jungfraujoch will most likely be a proxy for more mineral dust with reduced hygroscopicity and will therefore result in a lower $f(\mathrm{RH})$. For the other sites, an enlarged coarse mode points to an enlarged sea salt contribution, which, in contrast to mineral dust, is highly hygroscopic. Therefore, a simple proxy (like the Ångström exponent as a proxy for size) alone cannot be used to predict $f(\mathrm{RH})$ for other sites. Instead, information on the full size distribution is needed. For example, for the Arctic aerosol found in summer and fall in Ny-Ålesund in the Arctic, a single hygroscopicity ( $\kappa$-value) and measured size distribution together with a Mie model were found to be sufficient to calculate the ambient value of the scattering coefficient. The high variability of aerosol composition and size at Cabauw made a precise prediction of the scattering enhancement difficult. Here, only measurements of the full size distribution and the full size resolved chemical composition will make a

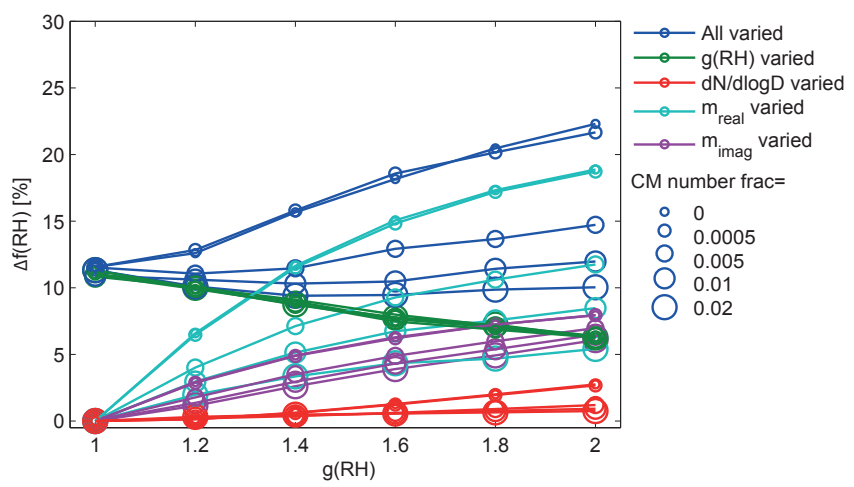

Fig. A1. Relative error $\triangle f(\mathrm{RH})$ of the calculated scattering enhancement using Monte Carlo simulation. The simulations were performed for different hygroscopic growth factors $g(\mathrm{RH})$ ( $x$ axis) and coarse mode number (CM) fractions (circle size). The simulations were repeated while keeping one of the individual input parameters constant (see legend).

good prediction of $f(\mathrm{RH})$ possible, if no explicit humidified nephelometer measurements are available. A comparison to the OPAC data set (Hess et al., 1998) showed a systematic overprediction of $f(\mathrm{RH})$, especially at intermediate $\mathrm{RH}$. The bias can be reduced if the implemented hygroscopic growth within OPAC is replaced by values in the current literature given here.

\section{Appendix A}

\section{Model uncertainty analysis}

A general uncertainty analysis of the predicted or calculated value of $f(\mathrm{RH})$ was performed using the Monte Carlo Method (Anderson, 1976). Here, the error propagation is done by repeated Mie calculations; for each calculation, the input parameters are varied randomly. 10000 iterations were made, although the results were already converged at less iterations (approx. 500). The calculations were made for $\lambda=550 \mathrm{~nm}$. For the hygroscopic growth factor (H-TDMA) and the fine mode particle number size distribution (SMPS or DMPSS) the error from the individual instrument was taken, while for the coarse mode particle number size distribution (OPSS) and refractive index (AMS, MAAP or aethalometer) assumptions about the uncertainty had to be made (see below). To test the sensitivity of the various input parameters, the Monte Carlo simulations were repeated each time, varying only one input parameter and keeping the other values and their mean value constant. In addition, the simulations were repeated for different hygroscopic growth factors (between 1 and 2) and coarse mode number fractions. For the hygroscopic growth factor, a normal error distribution with a standard deviation of 0.05 was assumed (Swietlicki et al., 2008). A bimodal size distribution was assumed 
with $N_{\mathrm{FM}}=10000$ and $N_{\mathrm{CM}}=200,100,50,1$ and 0 and $D_{\text {mod }}^{\mathrm{FM}}=100 \mathrm{~nm}$ and $D_{\mathrm{mod}}^{\mathrm{CM}}=1 \mu \mathrm{m}$ (with FM: fine mode and CM: coarse mode, see Eq. 7). The standard deviation of the mode was chosen to be $\sigma=2$ and assumed not to influence the error in $f(\mathrm{RH})$, since it would be included in the systematic error of the diameter sizing. For $N$ we assumed an error of $30 \%$ for the fine (SMPS and DMPSS) and $10 \%$ for the coarse mode (OPSS and APS), while for $D_{\text {mod }}$, we assumed a $10 \%$ uncertainty for the fine mode and $20 \%$ for the coarse mode (assuming a normal error distribution with the relative uncertainties recalculated to standard deviations). These uncertainties for the fine mode particles measured by the SMPS or DMPSS lie within the findings of Wiedensohler et al. (2012), while the uncertainties in the coarse mode sizing are assumptions based on our own measurements using the OPSS (Bukowiecki et al., 2011) and findings in the literature for the APS (Marshall et al., 1991; Putaud et al., 2000). However, it will be shown that the uncertainties within the absolute size distribution measurements are systematic uncertainties and eventually cancel out when calculating the ratio of $f(\mathrm{RH})$. The error of the refractive index cannot be accurately derived, so we have assumed a uniform (rectangular) distributed refractive index. The real part was randomly chosen from 1.4 to 1.8 , and the imaginary part was chosen from 0 to 0.1 . Both ranges cover the observations, e.g., of the inversely calculated values at Cabauw (Zieger et al., 2011), or the values given in Hess et al. (1998). Having an upper limit of 0.1 for the imaginary part is justified in our study because no pure absorbing substances were observed at the sites. The result is depicted in Fig. A1 as the relative error $\triangle f(\mathrm{RH})$, which is calculated from the standard deviation divided by the mean value, for different $g(\mathrm{RH})$ values and different coarse mode fractions. The overall relative uncertainty within the calculated $f(\mathrm{RH})$ is clearly below $15-25 \%$, which can be regarded as a very conservative estimation and is still sufficient despite the other strong simplifications that had to be made (spherical particles, homogeneous internally mixed particles, etc.).

The relative error increases with increasing $g(\mathrm{RH})$ (or increasing $\mathrm{RH}$ ) because the uncertainty due to the refractive index becomes less important for the wet scattering coefficient, which approaches the refractive index of water, while the wet scattering coefficient itself (in the denominator in Eq. (1) increases with increasing $g(\mathrm{RH})$. By contrast, the dry scattering coefficient (in the enumerator in Eq. (1)) and its high uncertainty stays unchanged, and thus the overall uncertainty in $f(\mathrm{RH})$ increases. The contribution of the real and imaginary parts to the relative error also increases with $g(\mathrm{RH})$ as can be seen by the cyan and violet curves in Fig. A1, while the contribution of the uncertainty in $g(\mathrm{RH})$ itself concurrently decreases. The particle number size distribution shows almost no effect because the uncertainty can be seen as a systematic error, which cancels out (only a minor effect of the diameter sizing can be expected, especially when no coarse mode is present). The relative error increases with decreasing coarse mode number fraction because the wet scattering coefficient increases more for pure, fine particles (those with a larger $f(\mathrm{RH})$ ) compared to an aerosol with an existing coarse mode. However, a non-existing or a negligible coarse mode number fraction is probably not relevant for the ambient (tropospheric) atmosphere and was also not observed in the studies presented here.

The relative error in the calculated $\triangle f(\mathrm{RH})$ decreases below $20 \%$ if a normally distributed uncertainty of the refractive index of $1.5 \pm 0.1$ (mean \pm standard deviation) for the real part and $0.02 \pm 0.002$ for the imaginary part are assumed for the refractive index uncertainty, which could be a more realistic assumption of the refractive index uncertainty than the rectangular distribution as used above. By contrast, $\triangle f(\mathrm{RH})$ can rise up to $35 \%$ if the uncertainty of $g(\mathrm{RH})$ is assumed to be $10 \%$, while the other input parameters have the same uncertainty as described above (both uncertainties refer to size distributions without coarse mode). This is a more reasonable uncertainty assumption for the cases in which the $g(\mathrm{RH})$ is predicted from AMS and MAAP, or for aethalometer measurements for cases without very strong sea salt, dust or BC influence (Gysel et al., 2007).

\section{Supplementary material related to this article is available online at http://www.atmos-chem-phys.net/13/ 10609/2013/acp-13-10609-2013-supplement.pdf.}

Acknowledgements. We thank all collaborators and co-authors of the related individual studies. Ralph Dlugi is acknowledged for providing the original data from Hänel and Zankl (1979). We thank the Norwegian Institute for Air Research (NILU) for providing the FLEXTRA trajectory calculations. This work was financially supported by the EC projects European Supersites for Atmospheric Aerosol Research (EUSAAR, contract 026140), Aerosols, Clouds, and Trace gases Research Infrastructure Network (ACTRIS, contract 262254) and Global Earth Observation and Monitoring (GEOMON, contract 026140), by MeteoSwiss in the framework of the Global Atmosphere Watch Program, as well as by the European Space Agency's Climate Change Initiative (aerosol_cci). The two anonymous reviewers are gratefully acknowledged for their detailed and helpful comments.

Edited by: A. Petzold

\section{References}

Anderson, G.: Error propagation by the Monte Carlo method in geochemical calculations, Geochim. Cosmochim. Ac., 40, 15331538, 1976.

Anderson, T., Covert, D., Marshall, S., Laucks, M., Charlson, R., Waggoner, A., Ogren, J., Caldow, R., Holm, R., Quant, F., Sem, G., Wiedensohler, A., Ahlquist, N., and Bates, T.: Performance 
characteristics of a high-sensitivity, three-wavelength, total scatter/backscatter nephelometer, J. Atmos. Ocean. Tech., 13, 967986, 1996

Birmili, W., Weinhold, K., Nordmann, S., Wiedensohler, A., Spindler, G., Müller, K., Herrmann, H., Gnauk, T., Pitz, M., Cyrys, J., Flentje, H., Nickel, C., Kuhlbusch, T., Löschau, G., Haase, D., Meinhardt, A., Schwerin, L., Ries, L., and Wirtz, K.: Atmospheric aerosol measurements in the German Ultrafine Aerosol Network (GUAN): Part 1: Soot and particle number concentration size distributions, Gefahrst. Reinh. Luft, 69, 137-145, 2009.

Bohren, C. and Huffman, D.: Absorption and Scattering of Light by Small Particles, Wiley-VCH, 2004.

Bukowiecki, N., Zieger, P., Weingartner, E., Jurányi, Z., Gysel, M., Neininger, B., Schneider, B., Hueglin, C., Ulrich, A., Wichser, A., Henne, S., Brunner, D., Kaegi, R., Schwikowski, M., Tobler, L., Wienhold, F. G., Engel, I., Buchmann, B., Peter, T., and Baltensperger, U.: Ground-based and airborne in-situ measurements of the Eyjafjallajökull volcanic aerosol plume in Switzerland in spring 2010, Atmos. Chem. Phys., 11, 10011-10030, doi:10.5194/acp-11-10011-2011, 2011.

Canagaratna, M., Jayne, J., Jimenez, J., Allan, J., Alfarra, M., Zhang, Q., Onasch, T., Drewnick, F., Coe, H., Middlebrook, A., Delia, A., Williams, L., Trimborn, A., Northway, M., DeCarlo, P., Kolb, C., Davidovits, P., and Worsnop, D.: Chemical and microphysical characterization of ambient aerosols with the Aerodyne aerosol mass spectrometer, Mass Spectrom. Rev., 26, 185-222, 2007.

Carrico, C., Rood, M., and Ogren, J.: Aerosol light scattering properties at Cape Grim, Tasmania, during the first Aerosol Characterization Experiment (ACE 1), J. Geophys. Res., 103, 1656516574, doi:10.1029/98JD00685, 1998.

Carrico, C., Rood, M., Ogren, J., Neusüß, C., Wiedensohler, A., and Heintzenberg, J.: Aerosol optical properties at Sagres, Portugal, during ACE-2, Tellus B, 52, 694-715, doi:10.1034/j.16000889.2000.00049.x, 2000.

Carrico, C., Kus, P., Rood, M., Quinn, P., and Bates, T.: Mixtures of pollution, dust, sea salt, and volcanic aerosol during ACE-Asia: Radiative properties as a function of relative humidity, J. Geophys. Res., 108, 8650, doi:10.1029/2003JD003405, 2003.

Charlson, R., Langner, J., Rodhe, H., Leovy, C., and Warren, S.: Perturbation of the northern hemisphere radiative balance by backscattering from anthropogenic sulfate aerosols, Tellus A, 43, 152-163, 1991.

Collaud Coen, M., Weingartner, E., Schaub, D., Hueglin, C., Corrigan, C., Henning, S., Schwikowski, M., and Baltensperger, U.: Saharan dust events at the Jungfraujoch: Detection by wavelength dependence of the single scattering albedo and first climatology analysis, Atmos. Chem. Phys., 4, 2465-2480, doi:10.5194/acp-4-2465-2004, 2004.

Collaud Coen, M., Weingartner, E., Apituley, A., Ceburnis, D., Fierz-Schmidhauser, R., Flentje, H., Henzing, J., Jennings, S., Moerman, M., Petzold, A., Schmid, O., and Baltensperger, U.: Minimizing light absorption measurement artifacts of the Aethalometer: Evaluation of five correction algorithms, Atmos. Meas. Tech., 3, 457-474, doi:10.5194/amt-3-457-2010, 2010.

DeCarlo, P., Kimmel, J., Trimborn, A., Northway, M., Jayne, J., Aiken, A., Gonin, M., Fuhrer, K., Horvath, T., Docherty, K., Worsnop, D. R., and Jimenez, J.: Field-deployable, high- resolution, time-of-flight aerosol mass spectrometer, Anal. Chem., 78, 8281-8289, 2006.

Ferrare, R., Melfi, S., Whiteman, D., Evans, K., and Leifer, R.: Raman lidar measurements of aerosol extinction and backscattering 1. Methods and comparisons, J. Geophys. Res., 103, 19663 19672, doi:10.1029/98JD01646, 1998.

Fierz-Schmidhauser, R., Zieger, P., Gysel, M., Kammermann, L., DeCarlo, P., Baltensperger, U., and Weingartner, E.: Measured and predicted aerosol light scattering enhancement factors at the high alpine site Jungfraujoch, Atmos. Chem. Phys., 10, 2319 2333, doi:10.5194/acp-10-2319-2010, 2010a.

Fierz-Schmidhauser, R., Zieger, P., Vaishya, A., Monahan, C., Bialek, J., O’Dowd, C. D., Jennings, S. G., Baltensperger, U., and Weingartner, E.: Light scattering enhancement factors in the marine boundary layer (Mace Head, Ireland), J. Geophys. Res., 115, D20204, doi:10.1029/2009jd013755, 2010 b.

Fierz-Schmidhauser, R., Zieger, P., Wehrle, G., Jefferson, A., Ogren, J., Baltensperger, U., and Weingartner, E.: Measurement of relative humidity dependent light scattering of aerosols, Atmos. Meas. Tech., 3, 39-50, doi:10.5194/amt-3-39-2010, $2010 \mathrm{c}$.

Fitzgerald, J., Hoppel, W., and Vietti, M.: The size and scattering coefficient of urban aerosol particles at Washington, DC as a function of relative humidity, J. Atmos. Sci., 39, 1838-1852, 1982.

Gasso, S., Hegg, D., Covert, D., Collins, D., Noone, K., Öström, E., Schmid, B., Russell, P., Livingston, J., Durkee, P., and Jonsson, H.: Influence of humidity on the aerosol scattering coefficient and its effect on the upwelling radiance during ACE-2, Tellus B, 52, 546-567, 2000.

Gysel, M., Crosier, J., Topping, D. O., Whitehead, J. D., Bower, K. N., Cubison, M. J., Williams, P. I., Flynn, M. J., McFiggans, G. B., and Coe, H.: Closure study between chemical composition and hygroscopic growth of aerosol particles during TORCH2, Atmos. Chem. Phys., 7, 6131-6144, doi:10.5194/acp-7-61312007, 2007.

Gysel, M., McFiggans, G., and Coe, H.: Inversion of tandem differential mobility analyser (TDMA) measurements, J. Aerosol Sci., 40, 134-151, doi:10.1016/j.jaerosci.2008.07.013, 2009.

Hale, G. and Querry, M.: Optical constants of water in the 200$\mathrm{nm}$ to $200-\mu \mathrm{m}$ wavelength region, Appl. Opt., 12, 555-563, doi:10.1364/AO.12.000555, 1973.

Hänel, G. and Zankl, B.: Aerosol size and relative humidity: Water uptake by mixtures of salts, Tellus, 31, 478-486, doi:10.1111/j.2153-3490.1979.tb00929.x, 1979.

Haywood, J. and Shine, K.: The effect of anthropogenic sulfate and soot aerosol on the clear sky planetary radiation budget, Geophys. Res. Lett., 22, 603-606, doi:10.1029/95GL00075, 1995.

Heim, M., Mullins, B. J., Umhauer, H., and Kasper, G.: Performance evaluation of three optical particle counters with an efficient "multimodal" calibration method, J. Aerosol Sci., 39, 1019-1031, 2008.

Henne, S., Brunner, D., Folini, D., Solberg, S., Klausen, J., and Buchmann, B.: Assessment of parameters describing representativeness of air quality in-situ measurement sites, Atmos. Chem. Phys., 10, 3561-3581, doi:10.5194/acp-10-3561-2010, 2010.

Hess, M., Koepke, P., and Schult, I.: Optical properties of aerosols and clouds: The software package OPAC, B. Am. Meteor. Soc., 79, 831-844, 1998. 
IPCC: Climate Change 2007: The Physical Science Basis. Contribution of Working Group I to the Fourth Assessment Report of the Intergovernmental Panel on Climate Change, Cambridge University Press, 2007.

Jurányi, Z., Gysel, M., Weingartner, E., DeCarlo, P., Kammermann, L., and Baltensperger, U.: Measured and modelled cloud condensation nuclei number concentration at the high alpine site Jungfraujoch, Atmos. Chem. Phys., 10, 7891-7906, doi:10.5194/acp-10-7891-2010, 2010.

Köhler, H.: The nucleus in and the growth of hygroscopic droplets, T. Faraday Soc., 32, 1152-1161, 1936.

Köpke, P., Hess, M., Schult, I., and Shettle, E.: Global aerosol data set, Max-Planck-Institut für Meteorologie, Report No. 243, 1997.

Kotchenruther, R. and Hobbs, P.: Humidification factors of aerosols from biomass burning in Brazil, J. Geophys. Res., 103, 3208132089, doi:10.1029/98JD00340, 1998.

Li-Jones, X., Maring, H., and Prospero, J.: Effect of relative humidity on light scattering by mineral dust aerosol as measured in the marine boundary layer over the tropical Atlantic Ocean, J. Geophys. Res., 103, 31113-31121, doi:10.1029/98JD01800, 1998.

Liu, B., Pui, D., Whitby, K., Kittelson, D., Kousaka, Y., and McKenzie, R.: Aerosol mobility chromatograph - new detector for sulfuric-acid aerosols, Atmos. Environ., 12, 99-104, 1978.

Lohmann, U. and Leck, C.: Importance of submicron surface-active organic aerosols for pristine Arctic clouds, Tellus B, 57, 261268, 2005

Marshall, I., Mitchell, J., and Griffiths, W.: The behaviour of regular-shaped non-spherical particles in a TSI aerodynamic particle sizer, J. Aerosol Sci., 22, 73-89, 1991.

McInnes, L., Bergin, M., Ogren, J., and Schwartz, S.: Apportionment of light scattering and hygroscopic growth to aerosol composition, Geophys. Res. Lett., 25, 513-516, doi:10.1029/98GL00127, 1998.

Mie, G.: Beiträge zur Optik trüber Medien, speziell kolloidalen Metalllösungen, Annalen der Physik, 25, 377-445, 1908.

Morgan, W., Allan, J., Bower, K., Esselborn, M., Harris, B., Henzing, J., Highwood, E. J., Kiendler-Scharr, A., McMeeking, G., Mensah, A., Northway, M., Osborne, S., Williams, P., Krejci, R., and Coe, H.: Enhancement of the aerosol direct radiative effect by semi-volatile aerosol components: Airborne measurements in North-Western Europe, Atmos. Chem. Phys., 10, 8151-8171, doi:10.5194/acp-10-8151-2010, 2010.

Nessler, R., Weingartner, E., and Baltensperger, U.: Adaptation of dry nephelometer measurements to ambient conditions at the Jungfraujoch, Environ. Sci. Technol., 39, 2219-2228, doi:10.1021/es035450g, 2005a.

Nessler, R., Weingartner, E., and Baltensperger, U.: Effect of humidity on aerosol light absorption and its implications for extinction and the single scattering albedo illustrated for a site in the lower free troposphere, J. Aerosol Sci., 36, 958-972, doi:10.1016/j.jaerosci.2004.11.012, 2005b.

Petters, M. and Kreidenweis, S.: A single parameter representation of hygroscopic growth and cloud condensation nucleus activity, Atmos. Chem. Phys., 7, 1961-1971, doi:10.5194/acp-71961-2007, 2007.

Petzold, A. and Schönlinner, M.: Multi-angle absorption photometry - a new method for the measurement of aerosol light absorption and atmospheric black carbon, J. Aerosol Sci., 35, 421-441, 2004.
Pilinis, C., Pandis, S., and Seinfeld, J.: Sensitivity of direct climate forcing by atmospheric aerosols to aerosol size and composition, J. Geophys. Res., 100, 18739-18754, doi:10.1029/95JD02119, 1995.

Putaud, J., Van Dingenen, R., Mangoni, M., Virkkula, A., Raes, F., Maring, H., Prospero, J., Swietlicki, E., Berg, O., Hillamo, R., and Mäkelä, T.: Chemical mass closure and assessment of the origin of the submicron aerosol in the marine boundary layer and the free troposphere at Tenerife during ACE-2, Tellus B, 52, 141$168,2000$.

Ramaswamy, V., Boucher, O., Haigh, J., Hauglustaine, D., and Haywood, J.: Radiative Forcing of Climate Change, Cambridge University Press, Cambridge, United Kingdom and New York, NY, USA, 2001.

Schwartz, S.: The Whitehouse Effect-Shortwave radiative forcing of climate by anthropogenic aerosols: An overview, J. Aerosol Sci., 27, 359-382, 1996.

Seinfeld, J. and Pandis, S.: Atmospheric Chemistry and Physics: From Air Pollution to Climate Change, John Wiley and Sons, Inc., Hoboken, New Jersey, 2006.

Sheridan, P., Delene, D., and Ogren, J.: Four years of continuous surface aerosol measurements from the Department of Energy's Atmospheric Radiation measurement Program Southern Great Plains Cloud and Radiation Testbed site, J. Geophys. Res., 106, 20735-20747, 2001.

Sjogren, S., Gysel, M., Weingartner, E., Alfarra, M., Duplissy, J., Cozic, J., Crosier, J., Coe, H., and Baltensperger, U.: Hygroscopicity of the submicrometer aerosol at the high-alpine site Jungfraujoch, $3580 \mathrm{~m}$ a.s.1., Switzerland, Atmos. Chem. Phys., 8, 5715-5729, doi:10.5194/acp-8-5715-2008, 2008.

Stohl, A. and Seibert, P.: Accuracy of trajectories as determined from the conservation of meteorological tracers, Q. J. Roy. Meteor. Soc., 124, 1465-1484, 1998.

Stohl, A., Wotawa, G., Seibert, P., and Kromp-Kolb, H.: Interpolation errors in wind fields as a function of spatial and temporal resolution and their impact on different types of kinematic trajectories, J. Appl. Meteorol., 34, 2149-2165, 1995.

Stokes, R. and Robinson, R.: Interactions in aqueous nonelectrolyte solutions. I. Solute-solvent equilibria, J. Phys. Chem., 70, 2126 2131, 1966.

Swietlicki, E., Hansson, H., Hämeri, K., Svenningsson, B., Massling, A., McFiggans, G., McMurry, P., Petäjä, T., Tunved, P., Gysel, M., Topping, D., Weingartner, E., Baltensperger, U., Rissler, J., Wiedensohler, A., and Kulmala, M.: Hygroscopic properties of submicrometer atmospheric aerosol particles measured with H-TDMA instruments in various environments - a review, Tellus B, 60, 432-469, 2008.

Topping, D. O., McFiggans, G. B., and Coe, H.: A curved multi-component aerosol hygroscopicity model framework: Part: Inorganic compounds, Atmos. Chem. Phys., 5, 1205-1222, doi:10.5194/acp-5-1205-2005, 2005.

Trenberth, K., Fasullo, J., and Kiehl, J.: Earth's global energy budget, B. Amer. Meteor. Soc., 90, 311-323, 2009.

Twomey, S.: Atmospheric Aerosols, Developments in Atmospheric Science, Elsevier, New York, USA, 1977.

Voss, K., Welton, E., Quinn, P., Frouin, R., Miller, M., and Reynolds, R.: Aerosol optical depth measurements during the Aerosols99 experiment, J. Geophys. Res., 106, 20821-20831, doi:10.1029/2000JD900783, 2001. 
Wang, W., Rood, M., Carrico, C., Covert, D., Quinn, P., and Bates, T.: Aerosol optical properties along the northeast coast of North America during the New England Air Quality Study - Intercontinental Transport and Chemical Transformation 2004 campaign and the influence of aerosol composition, J. Geophys. Res., 112, D10S23, doi:10.1029/2006JD007579, 2007.

Weingartner, E., Baltensperger, U., and Burtscher, H.: Growth and structural change of combustion aerosols at high relative humidity, Environ. Sci. Technol., 29, 2982-2986, 1995.

Weingartner, E., Saathoff, H., Schnaiter, M., Streit, N., Bitnar, B., and Baltensperger, U.: Absorption of light by soot particles: Determination of the absorption coefficient by means of Aethalometers, J. Aerosol Sci., 34, 1445-1465, 2003.

Wiedensohler, A., Birmili, W., Nowak, A., Sonntag, A., Weinhold, K., Merkel, M., Wehner, B., Tuch, T., Pfeifer, S., Fiebig, M., Fjäraa, A. M., Asmi, E., Sellegri, K., Depuy, R., Venzac, H., Villani, P., Laj, P., Aalto, P., Ogren, J. A., Swietlicki, E., Williams, P., Roldin, P., Quincey, P., Hüglin, C., Fierz-Schmidhauser, R., Gysel, M., Weingartner, E., Riccobono, F., Santos, S., Grüning, C., Faloon, K., Beddows, D., Harrison, R., Monahan, C., Jennings, S. G., O'Dowd, C. D., Marinoni, A., Horn, H.-G., Keck, L., Jiang, J., Scheckman, J., McMurry, P. H., Deng, Z., Zhao, C. S., Moerman, M., Henzing, B., de Leeuw, G., Löschau, G., and Bastian, S.: Mobility particle size spectrometers: harmonization of technical standards and data structure to facilitate high quality long-term observations of atmospheric particle number size distributions, Atmos. Meas. Tech., 5, 657-685, doi:10.5194/amt-5-657-2012, 2012.

WMO/GAW: Aerosol Measurement Procedures Guidelines and Recommendations, Report No. 153, World Meteorological Organization, Geneva, Switzerland, 2003.
Yan, P., Pan, X., Tang, J., Zhou, X., Zhang, R., and Zeng, L.: Hygroscopic growth of aerosol scattering coefficient: A comparative analysis between urban and suburban sites at winter in Beijing, Particuology, 7, 52-60, 2009.

Zieger, P., Fierz-Schmidhauser, R., Gysel, M., Ström, J., Henne, S., Yttri, K., Baltensperger, U., and Weingartner, E.: Effects of relative humidity on aerosol light scattering in the Arctic, Atmos. Chem. Phys., 10, 3875-3890, doi:10.5194/acp-10-38752010, 2010.

Zieger, P., Weingartner, E., Henzing, J., Moerman, M., de Leeuw, G., Mikkilä, J., Ehn, M., Petäjä, T., Clémer, K., van Roozendael, M., Yilmaz, S., Frieß, U., Irie, H., Wagner, T., Shaiganfar, R., Beirle, S., Apituley, A., Wilson, K., and Baltensperger, U.: Comparison of ambient aerosol extinction coefficients obtained from in-situ, MAX-DOAS and LIDAR measurements at Cabauw, Atmos. Chem. Phys., 11, 2603-2624, doi:10.5194/acp11-2603-2011, 2011.

Zieger, P., Kienast-Sjögren, E., Starace, M., von Bismarck, J., Bukowiecki, N., Baltensperger, U., Wienhold, F. G., Peter, T., Ruhtz, T., Collaud Coen, M., Vuilleumier, L., Maier, O., Emili, E., Popp, C., and Weingartner, E.: Spatial variation of aerosol optical properties around the high-alpine site Jungfraujoch (3580 m a.s.1.), Atmos. Chem. Phys., 12, 72317249, doi:10.5194/acp-12-7231-2012, 2012.

Zieger, P., Fierz-Schmidhauser, R., Poulain, L., Müller, T., Birmili, W., Spindler, G., Wiedensohler, A., Baltensperger, U., and Weingartner, E.: Influence of water uptake on the aerosol particle light scattering coeffcients of the Central European aerosol, Tellus B, in review, 2013. 